\title{
Calcium-driven regulation of voltage-sensing domains in
}

\section{BK channels}

Yenisleidy Lorenzo-Ceballos ${ }^{1,2}$, Willy Carrasquel-Ursulaez², Karen Castillo², Osvaldo Alvare $^{2,3}$ and Ramon Latorre ${ }^{2(*)}$

${ }^{1}$ Doctorado en Ciencias Mención Neurociencia, Facultad de Ciencias, Universidad de Valparaíso, Valparaíso, Chile; ${ }^{2}$ Centro Interdisciplinario de Neurociencia de Valparaíso, Facultad de Ciencias, Universidad de Valparaíso, Valparaíso, Chile; ${ }^{3}$ Departamento de Biología, Facultad de Ciencias, Universidad de Chile, Santiago, Chile.

(*) Correspondence and Requests for materials should be addressed to Ramon Latorre (ramon.latorre@uv.cl) 


\section{Abstract}

2 Allosteric interplays between voltage-sensing domains (VSD), $\mathrm{Ca}^{2+}$-binding sites, and the

3 pore domain govern the $\mathrm{Ca}^{2+}$ - and voltage-activated $\mathrm{K}^{+}(\mathrm{BK})$ channel opening. However,

4 the functional relevance of the $\mathrm{Ca}^{2+}$ - and voltage-sensing mechanisms crosstalk on $\mathrm{BK}$

5 channel gating is still debated. We examined the energetic interaction between $\mathrm{Ca}^{2+}$

6 binding and VSD activation measuring and analyzing the effects of internal $\mathrm{Ca}^{2+}$ on $\mathrm{BK}$

7 channels gating currents. Our results indicate that the $\mathrm{Ca}^{2+}$ sensors occupancy has a

8 strong impact on the VSD activation through a coordinated interaction mechanism in which

$9 \mathrm{Ca}^{2+}$ binding to a single $\alpha$-subunit affects all VSDs equally. Moreover, the two distinct high-

10 affinity $\mathrm{Ca}^{2+}$-binding sites contained in the C-terminus domains, RCK1 and RCK2, appear

11 to contribute equally to decrease the free energy necessary to activate the VSD. We

12 conclude that voltage-dependent gating and pore opening in BK channels is modulated to

13 a great extent by the interaction between $\mathrm{Ca}^{2+}$ sensors and VSDs. 


\section{Introduction}

15 Diverse cellular events involve calcium ions as a primary mediator in the signal

16 transduction pathways triggering, among other signaling processes, $\mathrm{Ca}^{2+}$-activated

17 conductances. Since the BK channels are regulated by cytosolic $\mathrm{Ca}^{2+}$ and depolarizing

18 voltages (Marty, 1981; Pallotta et al., 1981; Latorre et al., 1982), they are integrators of

19 physiological stimuli including intracellular $\mathrm{Ca}^{2+}$ elevation and membrane excitability. BK

20 channels are modular proteins where each module accomplishes a specific channel

21 function. Thus, different modules harbor voltage and $\mathrm{Ca}^{2+}$ sensors that communicate with

22 the channel gate allosterically (Cox et al., 1997; Horrigan and Aldrich, 1999, 2002;

23 Horrigan et al., 1999; Rothberg and Magleby, 1999, 2000; Cui and Aldrich, 2000).

24 Functional BK channels are formed by homotetramers of $\alpha$-subunits (Shen et al., 1994)

25 each comprising a transmembrane voltage-sensing domain (VSD) and an intracellular

$26 \mathrm{Ca}^{2+}$-sensing C-terminal domain (CTD) that can independently modulate the ion

27 conduction gate in the pore domain (PD) (Latorre et al., 2017). The CTDs consist of two

28 non-identical regulators of the conductance of $\mathrm{K}^{+}$domains ( $\mathrm{RCK} 1$ and $\left.\mathrm{RCK} 2\right)$ arranged

29 into a ring-like tetrameric structure dubbed the gating ring (Wu et al., 2010; Yuan et al.,

30 2010, 2012; Hite et al., 2017; Tao et al., 2017). Each RCK domain contains distinct ligand-

31 binding sites capable of detecting $\mathrm{Ca}^{2+}$ in the micromolar range (Schreiber and Salkoff,

32 1997; Bao et al., 2002; Xia et al., 2002).

33 In the absence of $\mathrm{Ca}^{2+}$, the activation of VSD decreases the free energy necessary to fully

34 open the BK channels in an allosteric fashion (Horrigan and Aldrich, 1999; Horrigan et al.,

35 1999). Under these experimental conditions, very positive membrane potentials are

36 required to drive all voltage sensors to its activated conformation (Cui et al., 1997; Stefani

37 et al., 1997; Horrigan et al., 1999; Contreras et al., 2012), ultimately leading to a significant

38 activity of the BK channel. Hence, in cells like neurons, an appreciable open probability of 
39 BK channels at physiologically relevant voltages necessarily involves the activation of $\mathrm{Ca}^{2+}$

40 sensors on the gating ring. The allosteric interplays established between the functional

41 and structural modules (VSD-PD, CTD-PD, and CTD-VSD) are key in enabling BK

42 channels to operate over a dynamic wide-range of internal $\mathrm{Ca}^{2+}$ and voltage conditions by

43 fine-tuning the channel's gating machinery. Therefore, understanding the structure-

44 functional bases that underlie the $\mathrm{Ca}^{2+}$ and voltage activation mechanisms

45 interrelationship becomes essential.

46 The voltage dependence of $\mathrm{Ca}^{2+}$-dependent gating ring rearrangements (Miranda et al.,

472013,2018 ) and RCK1 site occupancy (Sweet and Cox, 2008; Savalli et al., 2012; Miranda

48 et al., 2018) as well as the perturbation of VSD movements by $\mathrm{Ca}^{2+}$ binding (Savalli et al.,

49 2012) support the idea that the energetic interaction between both specialized sensors

50 may be crucial to favor BK channel activation. The physical CTD-VSD interface has been

51 suggested to provide the structure capable of mediating the crosstalk between these

52 sensory modules and their synergy in activating the pore domain (Yang et al., 2007; Sun

53 et al., 2013; Tao et al., 2017; Zhang et al., 2017). However, the strength of the interaction

54 between voltage and $\mathrm{Ca}^{2+}$ sensors and their relevance to $\mathrm{BK}$ channel activation is still an

55 unresolved matter (Horrigan and Aldrich, 2002; Carrasquel-Ursulaez et al., 2015). Also,

56 the functional role that plays each of the high-affinity $\mathrm{Ca}^{2+}$-binding sites on the CTD-VSD

57 allosteric interaction is an open question. The RCK1 and RCK2 $\mathrm{Ca}^{2+}$-binding sites have

58 distinct functional properties conferred by their different molecular structures and relative

59 positions within the gating ring (Wu et al., 2010; Yuan et al., 2010, 2012; Hite et al., 2017;

60 Tao et al., 2017). Thus, the RCK sites differ in their $\mathrm{Ca}^{2+}$ binding affinities (Bao et al., 2002;

61 Xia et al., 2002; Sweet and Cox, 2008), divalent cations selectivity (Oberhauser et al.,

62 1988; Schreiber and Salkoff, 1997; Zeng et al., 2005; Zhou et al., 2012), voltage

63 dependence (Sweet and Cox, 2008; Savalli et al., 2012; Miranda et al., 2018) and in their 
64 contribution to allosteric gating mechanism (Yang et al., 2010, 2015). In particular, only

65 the RCK1 site appears to be involved in communicating the $\mathrm{Ca}^{2+}$-dependent

66 conformational changes towards the membrane-spanning VSD (Savalli et al., 2012;

67 Miranda et al., 2018). Recently, the Aplysia BK structure shows that the N-lobe of RCK1

68 domain is in a non-covalent contact with the VSD and the S4-S5 linker being this RCK1-

69 VSD interaction surface rearranged when comparing the liganded and $\mathrm{Ca}^{2+}$-free

70 structures (Hite et al., 2017; Tao et al., 2017). Actually, it has been hypothesized that any

$71 \mathrm{Ca}^{2+}$-induced rearrangements of the gating ring should be ultimately transmitted to the

72 pore domain via the VSD (Hite et al., 2017; Zhou et al., 2017). Thus, defining what extent

$73 \mathrm{Ca}^{2+}$ binding influences to VSD is crucial in determining how important is the crosstalk

74 between sensors in decreasing the free energy necessary to open the BK channel.

75 Here, we examined the $\mathrm{Ca}^{2+}$-dependence of the VSD activation estimating the allosteric

76 coupling between $\mathrm{Ca}^{2+}$ and voltage sensors. By analyzing gating currents under

77 unliganded and $\mathrm{Ca}^{2+}$-saturated conditions, we found a strong energetic influence of the

$78 \mathrm{Ca}^{2+}$-binding on the voltage sensors equilibrium in an independent manner of the channel

79 opening. These findings point out that a major component in the synergistic $\mathrm{Ca}^{2+}$ and

80 voltage activation of BK channels can reside on the sensory domains communication. We

81 also found that the $\mathrm{Ca}^{2+}$-dependent behavior of the voltage sensor activation is consistent

82 with an CTD-VSD allosteric coupling that occurs through a concerted interaction scheme

83 where each $\mathrm{Ca}^{2+}$-bound to high-affinity sites affect equally all voltage sensors in the BK

84 tetramer. Notably, we found that the two distinct RCK1 and RCK2 $\mathrm{Ca}^{2+}$ sensors exert

85 equivalent contributions on VSD via independent allosteric pathways. 


\section{$86 \quad$ Results}

87 Allosteric coupling between $\mathrm{Ca}^{2+}$-binding and voltage sensor activation is strong.

88 We characterized the effects of $\mathrm{Ca}^{2+}$-binding on voltage sensor activation in BK channels

89 by analyzing gating current measured on inside-out patches of Xenopus laevis oocyte

90 membrane. Families of gating currents $\left(I_{G}\right)$ were evoked at different intracellular $\mathrm{Ca}^{2+}$

91 concentrations $\left(\left[\mathrm{Ca}^{2+}\right]_{i}\right)$ ranging from 0.1 to $100 \mu \mathrm{M}$ in $\mathrm{K}^{+}$-free solution (Figure 1A). For all

92 experiments, first we measured $I_{G}$ in the nominal absence of $\mathrm{Ca}^{2+}$ ("zero Ca ${ }^{2+"}$ condition),

93 and then we perfused the internal side with solutions containing $\mathrm{Ca}^{2+}$ at increasing

94 concentrations. The amount of gating charge displaced $\left(Q_{\mathrm{C}}\right)$ at each $\mathrm{Ca}^{2+}$ concentration

95 was obtained by fitting the initial part of the ON-gating current decay to a single exponential

96 (fast ON-gating; see Methods) and integrating it. In this manner, we determine only the

97 gating charge displaced before the BK channel opening.

98 The increase in internal $\mathrm{Ca}^{2+}$ promotes a leftward shift of the $Q_{\mathrm{C}}$ versus voltage $\left(Q_{\mathrm{C}}(V)\right)$

99 curves (Figure $1 B, C$ ) which indicate that $\mathrm{Ca}^{2+}$-binding facilitates the activation of the

100 voltage sensor being more prominent as binding sites occupancy increases. Revealing a

101 strong energetic interaction between both sensors, a significant $\mathrm{Ca}^{2+}$-induced shift of

102 voltage sensor activation occurs $\left(\Delta V_{\mathrm{H}}=-142.6 \pm 4.5 \mathrm{mV}\right)$ under $\mathrm{Ca}^{2+}$-saturated conditions

103 for high-affinity binding sites $(100 \mu \mathrm{M})$. Such large shift means that $\mathrm{Ca}^{2+}$-binding to the

$104 \mathrm{RCK} \mathrm{Ca}{ }^{2+}-$ binding sites alters the VSD equilibrium promoting a decrease in the free energy

$105\left(\Delta \Delta G_{V}^{C a}\right)$ that defines the voltage sensor resting-active (R-A) equilibrium by $\sim 8 \mathrm{~kJ} / \mathrm{mol}$

$106\left(\Delta \Delta G_{V}^{C a}=-7.98 \pm 0.27 \mathrm{~kJ} / \mathrm{mol}\right)$.

107 A visual inspection of the current records indicates that the kinetics of the ON-gating 108 current is not much affected by the concentration of $\mathrm{Ca}^{2+}$ present in the internal solution. 
109 However, it is apparent that the OFF-gating current is dramatically modified becoming

110 smaller in amplitude and with slower kinetics as the internal $\mathrm{Ca}^{2+}$ concentration is

111 increased (Figure 1A and Figure 1-figure supplement 1A). At least two components

112 can be resolved in the OFF gating current decay (Figure 1-figure supplement 1B,C),

113 and the relative contribution of the slower component increases as internal $\mathrm{Ca}^{2+}$

114 augmented reflecting an increase of the open probability of channel Figure 1-figure

115 supplement 1D,E). This kinetic behavior recapitulates the effect describe on gating

116 charge displacement as a function of the depolarizing pulse duration (Horrigan and

117 Aldrich, 2002; Contreras et al., 2012; Carrasquel-Ursulaez et al., 2015), and confirm that

118 this phenomenon is associated with the time course of channel opening revealing the

119 allosteric interaction between voltage sensors and the pore gate (Horrigan and Aldrich, 120 2002).

$121 \mathrm{Ca}^{2+}$ binding to single $\alpha$-subunit affects the R-A voltage sensor equilibrium of all

122 four subunits equally. Taking advantage of the dose-dependent effect of $\mathrm{Ca}^{2+}$ on voltage

123 sensor activation we investigated the underlying mechanism of the $\mathrm{Ca}^{2+}$-voltage sensors

124 communication in the context of the well-established Horrigan-Aldrich (HA) allosteric

125 gating model(Horrigan and Aldrich, 2002). Two different mechanisms were proposed by

126 Horrigan and Aldrich for the interaction between the $\mathrm{Ca}^{2+}$-binding sites and voltage

127 sensors. The first mechanism supposes that $\mathrm{Ca}^{2+}$ binding to one $\alpha$-subunit affects the VSD

128 in the same subunit only (Scheme I) (Figure 2A), while the second mechanism assumes

129 that the $\mathrm{Ca}^{2+}$ binding affects the four VSD equally (Scheme II) (Figure 2B). It should be

130 noted that the standard HA model makes two simplifying assumptions by considering a 
131 single $\mathrm{Ca}^{2+}$-binding site per $\alpha$-subunit and the Scheme I as the $\mathrm{Ca}^{2+}$ binding-VSD

132 interaction mechanism underlying BK channel gating (Horrigan and Aldrich, 2002).

133 For a better comprehension, we simulated the normalized $Q_{\mathrm{C}}(V)$ curves over a wide

134 range of $\mathrm{Ca}^{2+}$ concentrations (from 0 to $10 \mathrm{mM}$ ) for each $\mathrm{Ca}^{2+}-\mathrm{VSD}$ interaction scheme

135 (Figure 2C,D). Here we assume that the measurement of the fast gating currents captures

136 the charge displaced by R-A transitions and exclude the charge associated with the

137 transition between the activated estates. This assumption is reasonable since the $\mathrm{Ca}^{2+}$

138 binding rate constant estimated for $B K$ is about $10^{8} \mathrm{M}^{-1} \mathrm{~s}^{-1}$ (Hou et al., 2016) implying that

139 at $10 \mu \mathrm{M}$ internal $\mathrm{Ca}^{2+}$ (the highest non-saturating $\mathrm{Ca}^{2+}$ concentration tested) the time

140 constant of the $\mathrm{Ca}^{2+}$ binding is $1 \mathrm{~ms}$, while the VSD activates with a time constant of $\sim 30$

$141 \mu \mathrm{s}$ at the higher voltage tested (see the Supplementary Information for details of the

142 simulations). At extreme conditions of low $(0.03$ to $0.1 \mu \mathrm{M})$ and high $(\geq 100 \mu \mathrm{M})$ internal

$143 \mathrm{Ca}^{2+}$, the VSD activation behaves in a mechanism-independent manner since all voltage

144 sensors are in the same functional state (unliganded or saturated). However, the

145 distinctive effects on $Q_{\mathrm{C}}(V)$ curves at intermediate $\mathrm{Ca}^{2+}$ concentrations $(1-10 \mu \mathrm{M})$ provide

146 useful signatures to distinguish between these two mechanisms. Scheme I predicts two

147 functional states of the VSD depending on occupancy status of the $\mathrm{Ca}^{2+}$ site $\left(\mathrm{Ca}^{2+}\right.$ bound

148 and unbound) such that the $Q_{\mathrm{C}}(V)$ curve behavior is described by the fractional

149 distribution of the unliganded and $\mathrm{Ca}^{2+}$-saturated functional states like an all-or-none

150 allosteric effect (Figure 2C; Figure 2-figure supplement 1B and Equation 4 in

151 Supplementary Information). On the contrary, the $\mathrm{Ca}^{2+}$-binding effect on the VSD

152 activation according to the Scheme II is characterized by a five-component Boltzmann

153 function (Figure 2-figure supplement 1C and Equation 6 in Supplementary

154 Information). Each component represents a single functional state determined by the

155 number of $\mathrm{Ca}^{2+}$ bound to the channel (from 0 to 4). In such case, the $Q_{\mathrm{C}}(V)$ curves 
156 resulting from a distribution of functional states behaves as an equivalent single

157 Boltzmann leftward shifted by an incremental allosteric effect (from $E$ to $E^{4}$ ) as the

158 number of $\mathrm{Ca}^{2+}$ bound to the channel increases (Figure 2D).

159 To elucidate the mechanism by which $\mathrm{Ca}^{2+}$ and voltage sensors interact, we performed

160 fits of the $Q_{\mathrm{C}}(V)$ data using the two different models represented in the Scheme I and

161 Scheme II (Figure $3 \boldsymbol{A}, \boldsymbol{B})$. The allosteric factor $E$ that accounts for the coupling between

162 the $\mathrm{Ca}^{2+}$-binding sites and the voltage sensors was constrained to values calculated from

163 the experimental data of the $Q_{\mathrm{C}}(V)$ shift at the $\mathrm{Ca}^{2+}$ saturating conditions $(100 \mu \mathrm{M})$ in

164 relation to the same curve in the absence of $\mathrm{Ca}^{2+}$. The $z_{J}, J_{0}$ and $K_{D}$ parameters obtained

165 during the fitting procedure of each model are very similar (Figure 3C). The fitted values

166 of the affinity constant $\left(K_{D}=3-5 \mu \mathrm{M}\right)$ agree with previous reports (Cox et al., 1997;

167 Horrigan and Aldrich, 2002) although slightly smaller than those estimated on the closed

168 conformation of the channel $\left(K_{D}=11 \mu \mathrm{M}\right)$. However, we found that the fit with the Scheme

169 II to the $Q_{\mathrm{C}}(V)$ curves (Figure 3B) is better than the fit to the data using Scheme I (Figure

$1703 \boldsymbol{A}$ ) as indicated by the Akaike model selection criteria (AIC) (Akaike, 1974). Moreover,

171 Model II generates a $V_{\mathrm{H}^{-}}-\log \left[\mathrm{Ca}^{2+}\right]$ curve (solid line) that accounts for the dose-response

$172 V_{\mathrm{H}^{-}} \log \left[\mathrm{Ca}^{2+}\right]$ experimental data reasonable well (Figure 3D). Also, the behavior of

$173 Q_{\mathrm{C}}(V)$ curves at intermediate $\mathrm{Ca}^{2+}$ concentrations $(1-10 \mu \mathrm{M})$ is qualitatively consistent

174 with the phenotype exhibit by the $\mathrm{Ca}^{2+}-\mathrm{VSD}$ scheme II (Figure 2D and Figure 3B). Thus,

175 the experimental dose-dependent effect of $\mathrm{Ca}^{2+}$ on voltage sensor activation reveals that

$176 \mathrm{Ca}^{2+}$-binding to a single $\alpha$-subunit of $\mathrm{BK}$ channels increases $E$-fold the equilibrium

177 constant $J$ that defines the equilibrium between resting and active conformations of the

178 voltage sensors in all four subunits. 
179 High-affinity $\mathrm{Ca}^{2+}$-binding sites in RCK1 and RCK2 domains contribute equally to

180 the allosteric coupling between $\mathrm{Ca}^{2+}$ and voltage sensors. Under physiological

181 conditions, the RCK1 and RCK2 high-affinity $\mathrm{Ca}^{2+}$-binding sites are responsible by all

182 calcium sensitivity of the activation of BK channel (Schreiber and Salkoff, 1997; Bao et al.,

183 2002, 2004; Xia et al., 2002). However, distinct physiological roles of the RCK1 $\mathrm{Ca}^{2+}$

184 sensor and $\mathrm{Ca}^{2+}$ bowl may be based in their functionally and structurally distinctive

185 properties (Zeng et al., 2005; Sweet and Cox, 2008; Yang et al., 2010; Savalli et al., 2012;

186 Tao et al., 2017). Below, we asked what the energetic contribution to VSD equilibrium is

187 of the two high-affinity $\mathrm{Ca}^{2+}$-binding sites contained in the RCK1 and RCK2 domains.

188 To elucidate the effect of each $\mathrm{Ca}^{2+}$-sensor on the VSD activation we used mutations that

189 selectively and separately abolish the function of the two differents RCK Ca ${ }^{2+}$-sites.

190 Disruption of the RCK1 Ca $\mathrm{Ca}^{2+}$-sensor by the double mutant D362A/D367A (Xia et al., 2002)

191 reduces significantly $\left(48 \%, \Delta V_{\mathrm{H}}(\mathrm{D} 362 \mathrm{~A} / \mathrm{D} 367 \mathrm{~A})=-74.9 \pm 4.7 \mathrm{mV}\right)$ the leftward shifted of the

$192 Q_{\mathrm{C}}(V)$ curves at $100 \mu \mathrm{M} \mathrm{Ca}^{2+}$ compared with the wild-type (WT) BK channel (Figure

$193 \mathbf{4 A}, \boldsymbol{C}$ ). We also examined the effect of the mutant M513I (Bao et al., 2002) which have

194 been shown to eliminate the $\mathrm{Ca}^{2+}$ sensitivity derived from the RCK1 site (Bao et al., 2002,

195 2004; Zhang et al., 2010). In this mutant, the $100 \mu \mathrm{M} \mathrm{Ca}^{2+}$-induced shift in $V_{\mathrm{H}}$ of VSD

196 activation curve is also considerably smaller relative to WT (about $54 \%, \Delta V_{\mathrm{H}}(\mathrm{M} 513 \mathrm{l})=-$

$19765.4 \pm 2.6 \mathrm{mV}$ ) (Figure 5). Therefore, both mutations affect the $\mathrm{Ca}^{2+}$-induced

198 enhancement of activation of voltage sensor very similarly through the RCK1 site (Figure

199 5C), although their mechanisms action could be quite different. The M513 residue appears

200 to participate in the stabilization of the proper conformation $\mathrm{RCK} 1 \mathrm{Ca}^{2+}$-site whereas D367

201 is a key residue in the coordination of $\mathrm{Ca}^{2+}$ ion (Wu et al., 2010; Zhang et al., 2010; Tao

202 et al., 2017). On the other hand, neutralization of the residues forming part of the $\mathrm{Ca}^{2+}$

203 bowl (Schreiber and Salkoff, 1997) (5D5A mutant, see Methods) on the RCK2 domain 
204 decreases the leftward shift of the $Q_{\mathrm{C}}(V)$ curve when $\mathrm{Ca}^{2+}$ is increased to $100 \mu \mathrm{M}$ by

205 approximately $54 \%\left(\Delta V_{\mathrm{H}}(5 \mathrm{D} 5 \mathrm{~A})=-65.7 \pm 4.7 \mathrm{mV}\right)$ (Figure $\left.4 \boldsymbol{B}, \boldsymbol{D}\right)$. Surprisingly, the effect

206 of $\mathrm{Ca}^{2+}$ binding on $\Delta V_{\mathrm{H}}$ from each high-affinity $\mathrm{Ca}^{2+}$ site is roughly half relative to WT

207 channels with both intact sites (Figure 4E). Therefore, both high-affinity $\mathrm{Ca}^{2+}$-binding sites

208 contribute equally to decrease the free energy necessary to activate the VSD. Thus, the

209 change of free energy of the resting-active equilibrium of the voltage sensor in response

210 to $\mathrm{Ca}^{2+}$-binding at RCK2 site is $\sim-4 \mathrm{~kJ} / \mathrm{mol}\left(\Delta \Delta G_{V}^{C a}(\mathrm{D} 362 \mathrm{~A} / \mathrm{D} 367 \mathrm{~A})=-4.2 \pm 0.3 \mathrm{~kJ} / \mathrm{mol}\right.$ and

$\left.211 \Delta \Delta G_{V}^{C a}(\mathrm{M} 513 \mathrm{l})=-3.6 \pm 0.5 \mathrm{~kJ} / \mathrm{mol}\right)$ (Figure $4 C$ and Figure $5 C$ ). In the same way, the

212 occupation of the $\mathrm{RCK} 1 \mathrm{Ca}^{2+}$-binding site decreases the free energy necessary to activate

213 the VSD in $-3.8 \pm 0.4 \mathrm{~kJ} / \mathrm{mol}\left(\Delta \Delta G_{V}^{C a}{ }_{(5 \mathrm{D} 5 \mathrm{~A})}\right)$. Remarkably, these findings reveal an additive

214 effect of $\mathrm{Ca}^{2+}$-binding to the RCK1 and $\mathrm{Ca}^{2+}$ bowl sites on the VSD activation which

215 suggest independent allosteric pathways through which they exert their modulation on the

216 VSD.

217 Taking these results into account, we expanded the $\mathrm{Ca}^{2+}-\mathrm{VSD}$ interaction model described

218 by Scheme II considering the energetic contribution of the two kinds of $\mathrm{Ca}^{2+}$ sensors on

219 the VSD per a-subunit $\left(E_{W T}=E_{S 1} * E_{S 2}\right)$ (Figure 2-figure supplement 1E). As

220 described in the above model fittings, the allosteric factors $E$ of each one RCK1 and RCK2

221 sites $\left(E_{S 1}\right.$ and $\left.E_{S 2}\right)$ were constrained to values equivalent to the $\mathrm{Ca}^{2+}$-induced energetic 222 perturbations of the voltage sensor equilibrium for the 5D5A and D362A/D367A mutants, 223 respectively. However, the inclussion of the two $\mathrm{Ca}^{2+}$ sensors in the $\mathrm{Ca}^{2+}-\mathrm{VSD}$ interaction 224 model does not produce better fits to $Q_{\mathrm{C}}\left(V,\left[\mathrm{Ca}^{2+}\right]\right)$ according to the AIC criteria (Table

2251 and Figure 3B), the estimated $K_{D}$ parameters for each $\mathrm{Ca}^{2+}$-binding sites $\left(K_{D 1}=15.6\right.$

$226 \mu \mathrm{M}$ and $\left.K_{D 2}=1.9 \mu \mathrm{M}\right)$ by the experimental data fitting agrees very well with the apparent 
$227 \mathrm{Ca}^{2+}$ affinities previously reported in the literature (Bao et al., 2002; Xia et al., 2002; Sweet

228 and Cox, 2008). Interestingly, modest positive cooperativity $(G=2.6)$ between the two

$229 \mathrm{Ca}^{2+}$-binding sites located in the same a-subunit is required to achieve a good estimation

230 of the $K_{D}$ parameters (Table 1), where the $\mathrm{Ca}^{2+}$ bowl site has an affinity for $\mathrm{Ca}^{2+}$ about 8-

231 fold greater than does the $\mathrm{RCK} 1 \mathrm{Ca}^{2+}$-sensor. 


\section{Discussion}

233 Recent insights into a major interplay between voltage- and $\mathrm{Ca}^{2+}$-sensing modules in the

234 BK channel are supported by functional and structural studies (Yuan et al., 2010; Savalli

235 et al., 2012; Miranda et al., 2013, 2016, 2018; Carrasquel-Ursulaez et al., 2015; Hite et

236 al., 2017; Tao et al., 2017; Zhang et al., 2017), offering a new perspective in our

237 understanding of its multimodal gating mechanism. However, the CTD-VSD allosteric

238 coupling as well its molecular nature has yet to be firmly established since their direct

239 assessment is subject to great experimental challenges. Based on the functional

240 independence of the distinct structural domains (PD, CTD, and VSD), the energetic

241 relationship between the sensory modules can be directly defined comparing the voltage

242 sensor equilibrium change at extreme $\mathrm{Ca}^{2+}$ stimulus conditions limiting the status of the

$243 \mathrm{Ca}^{2+}$-binding sites to two well-defined configurations: unliganded and saturated (Horrigan

244 and Aldrich, 2002).

245 Using this approach, this work straightforwardly establishes that $\mathrm{Ca}^{2+}$-binding to high-

246 affinity sites make a significant and direct energetic contribution to the equilibrium of the

247 resting-activated transition $(\mathrm{R}-\mathrm{A})$ of the VSD facilitating their activation $\left(\Delta V_{\mathrm{H}}=-142.6 \pm\right.$

$2484.5 \mathrm{mV}$ and $\left.\Delta \Delta G_{V}^{C a}=-7.98 \pm 0.27 \mathrm{~kJ} / \mathrm{mol}\right)$. This result resolves a previous debate

249 regarding to the magnitude of the $\mathrm{Ca}^{2+}$-driven shift of the $Q_{\mathrm{C}}(V)$ curve, because it has

250 been reported a similar leftward shift $\left(\Delta V_{\mathrm{H}}=-140 \mathrm{mV}\right.$ and $\Delta \Delta G_{V}^{C a}=-7.9 \mathrm{~kJ} / \mathrm{mol}$; at $\left[\mathrm{Ca}^{2+}\right]_{\mathrm{i}}$

$251=100 \mu \mathrm{M})\left(\right.$ Carrasquel-Ursulaez et al., 2015) and a smaller leftward shift $\left(\Delta V_{\mathrm{H}}=-33 \mathrm{mV}\right.$

252 and $\Delta \Delta G_{V}^{C a}=-1.9 \mathrm{~kJ} / \mathrm{mol}$; at $\left.\left[\mathrm{Ca}^{2+}\right]_{\mathrm{i}}=70 \mu \mathrm{M}\right)$ (Horrigan and Aldrich, 2002) at saturating

$253 \mathrm{Ca}^{2+}$ concentration. The reason for the contradictory findings is not clear to us; since we

254 used a similar experimental approach. Even if we assumed that the calcium effect on VSD

255 is underestimated at $70 \mu \mathrm{M} \mathrm{Ca}^{2+}$ (Horrigan and Aldrich, 2002) compared to $100 \mu \mathrm{M}$ as 
256 saturating condition of the binding sites, we observed a significative greater effect in $\mathrm{Ca}^{2+}$

257 concentrations (1, 5 and $10 \mu \mathrm{M}$, Figure 1 C) where less than $50 \%$ of the $\mathrm{Ca}^{2+}$ sensors are

258 occupied $\left(K_{D}=11 \mu \mathrm{M}\right.$ (Cox et al., 1997; Horrigan and Aldrich, 2002)).

259 Fluorescence studies that optically track the motions of the voltage sensor or gating ring 260 provide two lines of evidence that support these findings. First, conformational 261 rearrangements of the voltage sensors detected using voltage-clamp fluorometry can be

262 provoked by $\mathrm{Ca}^{2+}$-binding to the high-affinity sites. The sudden rise of intracellular $\left[\mathrm{Ca}^{2+}\right]$

263 by UV flash induced-photolysis of caged $\mathrm{Ca}^{2+}$ prompts a leftward shift in both 264 conductance-voltage $(G(V))$ and fluorescence-voltage $(F(V))$ relationships. These

265 results suggest that functional activation of the gating ring is propagated to VSD leading

266 to structural perturbations of voltages sensors, thereby favoring its active conformation

267 (Savalli et al., 2012). Second, the structural rearrangement of gating ring in response to

$268 \mathrm{Ca}^{2+}$ has a voltage dependence (Miranda et al., 2013, 2018) attributable to the voltage

269 sensor operation. The origin of these voltage-dependent motions has been recently

270 established via modifications on the voltage-sensing function of the BK channel using the

271 patch-clamp fluorometry technique (Miranda et al., 2018). Both the charged residue

272 mutations on the S4 transmembrane segment (R210, R213, and E219) and the co-

273 expression of $\beta 1$-subunit with BKa channel modify the conformational changes of the

274 gating ring triggered by depolarization in correspondence to the observed $G(V)$ shift for

275 these channel constructs. In contrast, perturbations of pore opening equilibrium like the

276 F315A mutation or the assembly of BKa channel with y1-subunit does not modify on the

277 voltage-dependent reorganization of the gating ring (Miranda et al., 2018).

278 Mechanistically and in a channel opening-independent fashion, how does the CTD-VSD 279 coupling occur? Taking into account the homotetrameric configuration of the BK channel, 280 Horrigan and Aldrich (Horrigan and Aldrich, 2002) defined the general gating scheme of 
281 BK channel considering the simplest CTD-VSD interaction model in which voltage sensors

282 and $\mathrm{Ca}^{2+}$-binding sites solely interact within the same subunit. However, the VSD

283 movement at non-saturating $\mathrm{Ca}^{2+}$ conditions which entail distinct functional states of the

$284 \mathrm{Ca}^{2+}$ sites (unliganded and liganded), unveiled that the standard HA model can not explain

285 the mechanistic interaction governing the allosteric coupling between the $\mathrm{Ca}^{2+}$ and voltage

286 sensors. Given that $\mathrm{Ca}^{2+}$-binding will influence only a fraction of voltage sensors, Scheme

287 I would evidence $Q_{\mathrm{C}}(V)$ curves characteristic of an all-or-none model showing two well-

288 distinguishable components Boltzmann that correspond to $\mathrm{Ca}^{2+}$-affected and unaffected

289 VSD fractions (Figure 3A). Conversely, an energetic effect of each $\mathrm{Ca}^{2+}$-site on all the

290 voltage sensors of the tetramer would lead to an equivalent functional status of each VSD,

291 so that the $Q_{\mathrm{C}}(V)$ curves behaving in an incremental shifted fashion as increasing the

292 fractional occupancy of the $\mathrm{Ca}^{2+}$ sites. The VSD and $\mathrm{Ca}^{2+}$ sites interacting in such a fashion

293 (Scheme II) reproduce reasonably well the behavior of the $\mathrm{Ca}^{2+}$-dependent gating charge

294 movement observed in our experiments (Figure 3B). This concerted CTD-VSD

295 communication may underlie a mechanism analogous to the mechanical strategy of

296 interaction between the homooctameric ring of RCK domains and the pore module

297 described for bacterial $\mathrm{K}^{+}$channels (Jiang et al., 2002; Ye et al., 2006; Lingle, 2007; Pau

298 et al., 2011; Smith et al., 2012, 2013). Both in MthK and BK channels, the $\mathrm{Ca}^{2+}$-site

299 occupancy triggers a conformational change conveying to a symmetric overall

300 rearrangement of the cytosolic tetrameric structure that finally is propagated to the

301 transmembrane regions (TMD) via C-linker and in the BK channel also via the protein-

302 protein interfaces between the gating ring and the TMD (Jiang et al., 2002, 2003; Ye et

303 al., 2006; Yuan et al., 2010, 2012; Pau et al., 2011; Smith et al., 2012; Tao et al., 2017).

304 Consequently, we can speculate that each $\mathrm{Ca}^{2+-}$-binding event produces a gradual 
305 conformational expansion of the gating ring affecting the four voltage sensors in each step

306 through the progressive perturbations within the protein-protein interfaces.

307 As mentioned above, the communication pathway through which the $\mathrm{Ca}^{2+}$-driven 308 conformational changes are propagated to the voltage sensors appears to critically reside 309 on the CTD-VSD interface that involves non-covalent interactions between RCK1 N-lobe 310 and S0-S4 transmembrane segments (Yang et al., 2007, 2008, 2010; Sun et al., 2013;

311 Hite et al., 2017; Tao et al., 2017). Scanning mutagenesis of RCK1-N terminal subdomain

312 indicated that residues on the $\beta \mathrm{A}-\alpha \mathrm{C}$ region are involved into the allosteric connection of 313 the $\mathrm{Ca}^{2+}$-dependent activation mediated by RCK1 site occupancy but not to the $\mathrm{Ca}^{2+}$ bowl 314 (Yang et al., 2010). In line with this study, the selective activation of the RCK1 domain was 315 identified to be responsible for the $\mathrm{Ca}^{2+}$-induced VSD rearrangement (Savalli et al., 2012) 316 and the voltage dependence of the $\mathrm{Ca}^{2+}$-driven motions of gating ring (Miranda et al., $3172016,2018)$, suggesting that CTD-VSD allosteric coupling is primarily determined by the 318 RCK1 site. However, our results are inconsistent with this picture. The constructs 319 D362A/D367A and 5D5A (D894A-D898A) selectively impaired the $\mathrm{Ca}^{2+}$-sensitivity of the 320 RCK1- and RCK2-sensors, respectively, by neutralization of residues that are involved in 321 contributing to $\mathrm{Ca}^{2+}$-coordination (Zhang et al., 2010; Tao et al., 2017). Comparing the fast 322 gating charge movement at $0 \mathrm{Ca}^{2+}$ and saturating $\mathrm{Ca}^{2+}$ conditions reflects that the 323 energetic effect of $\mathrm{Ca}^{2+}$-binding on voltage sensor equilibrium is practically identical ( -4 $324 \mathrm{~kJ} / \mathrm{mol}$ ) for either the D362A/D367A mutations or 5D5A mutations (Figure 4). Thus, our 325 findings establish that the RCK2-driven contribution to CTD-VSD energetic coupling is 326 quite similar to the RCK1-driven contribution. The functional role of the RCK2-sensor on $327 \mathrm{Ca}^{2+}$-sensitivity of VSD activation was further corroborated using the M513I mutation 328 (Figure 5). This point mutation hinders the $\mathrm{Ca}^{2+}$-dependent activation associated with the 329 RCK1-sensor presumably by disrupting the structural integrity of the binding site and the 
330 transduction via through the $\beta A-\alpha C$ region (Zhang et al., 2010). Thus, another residue

331 involved in the $\mathrm{BK} \mathrm{Ca}{ }^{2+}$-dependent activation mediated by the $\mathrm{RCK} 1 \mathrm{Ca}^{2+}$-binding site but

332 not forming part of the site itself decreases the $Q_{\mathrm{C}}(V)$ leftward shift almost in the same

333 amount as it does the D362A/D367A mutant.

334 Interestingly, beyond the energetic contribution of each RCK site to the voltage sensor 335 equilibrium is the same, its addition mimics the VSD $\mathrm{Ca}^{2+}$-sensitivity of the fully occupied 336 sites. These findings remind us of early reports showing that each RCK site mutant shifts

337 the $\mathrm{Ca}^{2+}$-dependent $G(V)$ by approximately half relative to WT channels (Bao et al., 2002;

338 Xia et al., 2002). Our results suggest an autonomy of the two RCK-sensors indicating 339 independent allosteric pathways through which they exert their modulation on the VSD but 340 does not discard some cooperativity effect between them. Indeed, various lines of 341 evidence indicate albeit modest a cooperativity between the two high-affinity $\mathrm{Ca}^{2+}$-binding 342 sites although their nature is still unclear (Qian et al., 2006; Sweet and Cox, 2008; Savalli 343 et al., 2012). Intra and intersubunit structural connectivity support the putative cooperative 344 interactions between the $\mathrm{Ca}^{2+}$ sensors at the gating ring (Yuan et al., 2012; Hite et al., 345 2017). Actually, a recently functional study of the intrasubunit connections between the 346 RCK1 site and $\mathrm{Ca}^{2+}$ bowl (R514-Y904/E902 interactions) has shown that such

347 connections are potential candidates of the structural determinants underlying to a 348 cooperative mechanism between the RCK1- and RCK2-sensor involving either to 349 preserve the integrity of $\mathrm{RCK} 1 \mathrm{Ca}^{2+}$-binding site or the allosteric propagation pathway 350 towards transmembrane domains (Kshatri et al., 2018). On the basis of the cryo-EM 351 structure of Aplysia californica BK channel, Hite et al. (Hite et al., 2017) proposed that 352 there should be a positive cooperativity of the $\mathrm{Ca}^{2+-}$-binding at $\mathrm{RCK} 1$ site and $\mathrm{Ca}^{2+}$ bowl 353 since the $\mathrm{Ca}^{2+}$-induced conformational change of the RCK1-N lobes from closed to open 354 configuration depends on functional state (unliganded and liganded) of both RCK sites. 
355 Our analysis based on the CTD-VSD interaction model predicted a small and positive

356 cooperative relation $(G=2.6)$ among the two high-affinity $\mathrm{Ca}^{2+}$ sites within the same $\alpha$ -

357 subunit, which has been suggested by an earlier study (Qian et al., 2006). It is noteworthy

358 that $K_{D}$ parameters achieved for each $\mathrm{Ca}^{2+}$-binding sites $\left(K_{D 1}=15.6 \mu \mathrm{M}\right.$ and $K_{D 2}=1.9$

$359 \mu \mathrm{M})$ by the experimental data fitting agrees very well with the apparent $\mathrm{Ca}^{2+}$ affinities

360 previously reported in the literature (Bao et al., 2002; Xia et al., 2002; Sweet and Cox,

361 2008). Together, all this new information recapitulate a more relevant functional role of the

362 cooperative interactions between $\mathrm{RCK}$ sensors within the same subunit on $\mathrm{Ca}^{2+}$

363 dependent activation of the channel (Qian et al., 2006).

364 In conclusion, our results depict a remarkable, and direct energetic direct interplay

365 between the specialized sensory modules (VSD and CTD). Our findings together with the

366 emerging structural-functional information establish a new paradigm about how the stimuli

367 integration (depolarization and intracellular $\mathrm{Ca}^{2+}$ ) modulates the $\mathrm{BK}$ channel activation and

368 its relevance within a physiological context. Notable and unexpected is the equivalent role

369 of the distinct ligand-binding sites at the cytosolic domain to the allosteric regulation on

370 voltage sensing. Additional studies to discern the molecular bases underlying in the $\mathrm{Ca}^{2+}$

371 and voltage propagation pathways and the cooperative interactions of the RCK1 and

372 RCK2 regulatory domains may provide new clues about the dual gating mechanism of BK

373 channel. 


\section{Methods}

\section{Channel Expression.}

376 Xenopus laevis oocytes were used as a heterologous system to express BK channels.

377 The cDNA coding for the human BK a-subunit (U11058) was provided by L. Toro

378 (University of California, Los Angeles, CA). The cDNA coding for independent mutants of

379 each two high-affinity $\mathrm{Ca}^{2+}$ site from BK channel, the double mutant D362A/D367A (Xia et

380 al., 2002) and the mutant M513I (Bao et al., 2002) in the RCK1 Ca+-binding site and the

381 mutant 5D5A (Schreiber and Salkoff, 1997) (D894A/D895A/D896A/D897A/D898A) in the

382 RCK2 $\mathrm{Ca}^{2+}$-binding site or calcium bowl, were kindly provided by M. Holmgren (National

383 Institutes of Health, Bethesda, MD). The cRNA was prepared by using mMESSAGE

384 mMACHINE (Ambion) for in vitro transcription. Xenopus laevis oocytes were injected with

$38550 \mathrm{ng}$ of cRNA and incubated in an ND96 solution (in mM: $96 \mathrm{NaCl}, 2 \mathrm{KCl}, 1.8 \mathrm{CaCl}_{2}, 1$

$\left.386 \mathrm{MgCl}_{2}, 5 \mathrm{HEPES}, \mathrm{pH} 7.4\right)$ at $18^{\circ} \mathrm{C}$ for $4-8$ days before electrophysiological recordings.

\section{Electrophysiological recordings.}

388 All recordings were made by using the patch-clamp technique in the inside-out 389 configuration. Data were acquired with an Axopatch 200B (Molecular Devices) amplifier 390 and the Clampex 10 (Molecular Devices) acquisition software. Gating current $\left(I_{G}\right)$ records 391 were elicited by 1 -ms voltage steps from -90 to $350 \mathrm{mV}$ in increments of $10 \mathrm{mV}$. Both the

392 voltage command and current output were filtered at $20 \mathrm{kHz}$ with 8-pole Bessel low-pass

393 filter (Frequency Devices). Current signals were sampled with a 16-bit A/D converter

394 (Digidata 1550B; Molecular Devices), using a sampling rate of $500 \mathrm{kHz}$. Linear membrane

395 capacitance and leak subtraction were performed based on a P/4 protocol (Armstrong and

396 Bezanilla, 1974). 
397 Borosilicate capillary glasses (1B150F-4, World Precision Instruments) were pulled in a

398 horizontal pipette puller (Sutter Instruments). After fire-polished, pipette resistance was

399 0.5-1 M . The external (pipette) solution contained (in $\mathrm{mM}$ ): 110 tetraethylammonium

400 (TEA)- $\mathrm{MeSO}_{3}, 10 \mathrm{HEPES}, 2 \mathrm{MgCl}$; $\mathrm{pH}$ was adjusted to 7.0. The internal solution (bath)

401 contained (in mM): N-methyl-D-glucamine (NMDG)-MeSO $3,10 \mathrm{HEPES}$, and 5 EGTA for

402 "zero $\mathrm{Ca}^{2+"}$ solution ( $\sim 0.8 \mathrm{nM}$, based on the presence of $\sim 10 \mu \mathrm{M}$ contaminant $\left[\mathrm{Ca}^{2+}\right]$ (Cui

403 et al., 1997). For test solutions at different $\mathrm{Ca}^{2+}$ concentrations $(0.1-100 \mu \mathrm{M}), \mathrm{CaCl}_{2}$ was

404 added to reach the desired free $\left[\mathrm{Ca}^{2+}\right]$, and $5 \mathrm{mM} \mathrm{EGTA}(0.1-0.5 \mu \mathrm{M})$ or HEDTA $(1-10 \mu \mathrm{M})$

405 was used as calcium buffer. No $\mathrm{Ca}^{2+}$ chelator was used in $100 \mu \mathrm{M}$ free $\mathrm{Ca}^{2+}$ solutions.

406 Free calcium concentration was estimated using the WinMaxChelator Software and

407 checked with a $\mathrm{Ca}^{2+}$-electrode (Hanna Instruments). All experiments were performed at

408 room temperature $\left(20-22^{\circ} \mathrm{C}\right)$. To measure $I_{G}$ at different $\mathrm{Ca}^{2+}$ concentrations in the same

409 oocyte, the patch was excised and washed with an appropriate internal solution at least

41010 times the chamber volume.

\section{Data Analysis.}

412 All data analysis was performed using Clampfit 10 (Molecular Devices), Matlab

413 (MathWorks) and Excel 2007 (Microsoft). The first 50-100 $\mu$ s of the ON-gating currents

414 were fitted to a single exponential function and the area under the curve was integrated to

415 obtain the charge displaced between closed states $\left(Q_{\mathrm{C}}\right)$ (Horrigan and Aldrich, 1999,

416 2002; Contreras et al., 2012; Carrasquel-Ursulaez et al., 2015). $Q_{\mathrm{C}}(V)$ data for each

$417\left[\mathrm{Ca}^{2+}\right]_{i}$ were fitted using a Boltzmann function: $Q_{\mathrm{C}}(V)=\frac{Q_{\mathrm{C}, \mathrm{MAX}}}{1+e^{\left(\frac{-z_{Q} F\left(V-V_{\mathrm{H}}\right)}{R T}\right)}}$, where

$418 Q_{\mathrm{C}}$, MAX is the maximum charge, $z_{Q}$ is the voltage dependency of activation, $V_{\mathrm{H}}$ is the

419 half-activation voltage, $T$ is the absolute temperature (typically $295 \mathrm{~K}$ ), $F$ is the Faraday's 
420 constant, and $R$ is the universal gas constant. $Q_{\mathrm{C}}, \mathrm{MAX}, V_{\mathrm{H}}$, and $z_{Q}$ were determined

421 using least square minimization. $Q_{\mathrm{C}}(V)$ curves were aligned by shifting them along the

422 voltage axis by the mean $\Delta V=\left(\left\langle V_{\mathrm{H}}\right\rangle-V_{\mathrm{H}}\right)$ to generate a mean curve that did not alter

423 the voltage dependence (Horrigan and Aldrich, 1999). All error estimates are SEM.

424 The $\mathrm{Ca}^{2+}$-induced effect on VSD activation was quantified as the $V_{\mathrm{H}}$ shift relative to "zero"

425 Ca ${ }^{2+}$ condition: $\Delta V_{\mathrm{H}}=V_{\mathrm{H}\left(\left[\mathrm{Ca}^{2+}\right]_{i}\right)}-V_{\mathrm{H}\left(0\left[\mathrm{Ca}^{2+}\right]_{i}\right)}$. For wild-type (WT) BK channel and

426 the RCK Ca ${ }^{2+}$-sensor mutants (D362A/D367A, M513I and 5D5A), the energetic

427 contribution of $\mathrm{Ca}^{2+}$-binding on resting-active $(\mathrm{R}-\mathrm{A})$ equilibrium of the voltage sensor was

428 calculated as changes in Gibbs free energy of VSD activation induced by $100 \mu \mathrm{M} \mathrm{Ca}^{2+}$ :

$429 \Delta \Delta G_{V}^{C a}=F\left(Z_{Q\left(100 \mu \mathrm{M}\left[\mathrm{Ca}^{2+}\right]_{i}\right)} V_{\mathrm{H}\left(100 \mu \mathrm{M}\left[\mathrm{Ca}^{2+}\right]_{i}\right)}-Z_{Q\left(0\left[\mathrm{Ca}^{2+}\right]_{i}\right)} V_{\mathrm{H}\left(0\left[\mathrm{Ca}^{2+}\right]_{i}\right)}\right)$.

\section{$430 \quad$ Model fitting.}

431 We fit the $Q_{\mathrm{C}}\left(V,\left[\mathrm{Ca}^{2+}\right]\right)$ experimental data using two distinct interaction mechanism

432 between $\mathrm{Ca}^{2+}$-binding sites and voltage sensor (see Scheme I and Scheme II in the Figure

$4332 \boldsymbol{A}, \boldsymbol{B}$ ) within the framework of Horrigan-Aldrich (HA) general allosteric model (Horrigan

434 and Aldrich, 2002). Assumptions and considerations for the equations that describe each

435 one of the $\mathrm{Ca}^{2+}-\mathrm{VSD}$ interaction schemes are given in the Supplementary Information. In

436 terms of the HA allosteric mechanisms, the voltage sensor R-A equilibrium is defined by

437 the equilibrium constant $J$ according to the relation $J=e^{\frac{z_{J} F\left(V-V_{\mathrm{H}}\right)}{R T}}=J_{0} e^{\frac{z_{J} F V}{R T}}$, where $J_{0}$

438 is the zero voltage equilibrium constant and $z_{J}$ the gating charges displacement per

439 voltage sensor. In this fashion, the fraction of the total charge displaced essentially

440 between closed states, $\left(Q_{\mathrm{C}}(V) / Q_{\mathrm{C}}\right.$, MAX $)$ in the absence of calcium can be written as: 
$441 Q_{\mathrm{C}}(V) / Q_{\mathrm{C}, \operatorname{MAX}}\left(\mathrm{Ca}^{2+} \ll K_{D}\right)=\frac{1}{1+J^{-1}}$, where $K_{D}$ is the dissociation constant of the

442 high-affinity calcium-binding site with all voltage sensors at rest and the channel closed.

443 In the presence of saturating $\mathrm{Ca}^{2+}(100 \mu \mathrm{M})$, the equilibrium of the R-A transition $J$

444 becomes amplified by the allosteric factor $E$, which defines the coupling between $\mathrm{Ca}^{2+}$

445 binding sites and voltage sensors, being $Q_{\mathrm{C}}(V) / Q_{\mathrm{C}, \operatorname{MAX}}\left(\mathrm{Ca}^{2+} \gg K_{D}\right)=\frac{1}{1+(J E)^{-1}}$

446 and $J E=J_{0} e^{\frac{R T \ln (E)+z_{J} F V}{R T}}$. The $Q_{\mathrm{C}}(V) / Q_{\mathrm{C}}$, MAX measured in the presence of high

$447\left[\mathrm{Ca}^{2+}\right]$ and "zero $\mathrm{Ca}^{2+"}$ condition at the same voltage (so that $J$ be canceled out) but in the

448 limit where voltage where $J^{-1} \gg 1$ is :

449

$$
\frac{Q_{\mathrm{C}}(V) / Q_{\mathrm{C}, \operatorname{MAx}}\left(\mathrm{Ca}^{2+} \gg K_{D}\right)}{Q_{\mathrm{C}}(V) / Q_{\mathrm{C}, \operatorname{MAx}}\left(\mathrm{Ca}^{2+} \ll K_{D}\right)} \underset{\left(\lim J^{-1} \gg 1\right)}{=}=\frac{J E}{J}=E
$$

450 Thus, the Gibbs free energy perturbation of the voltage sensor R-A equilibrium when the 451 high-affinity binding sites are approximately $100 \%$ occupied by $\mathrm{Ca}^{2+}(100 \mu \mathrm{M})$ is a 452 straightforward measure of the allosteric factor $E: \quad E=e^{-\Delta \Delta G_{V}^{C a} / R T}$.

453 Based on these conditions, the allosteric parameter $E$ values were calculated and

454 introduced in each of the two $\mathrm{Ca}^{2+}-\mathrm{VSD}$ interaction models as a fixed parameter. Once $E$

455 was obtained, the families of $Q_{\mathrm{C}}\left(V,\left[\mathrm{Ca}^{2+}\right]\right)$ curves were simultaneously fitted to the

456 model equations (Equation 3 and Equation 6) (see Supplementary information) by

457 minimizing least-squares estimating the $Z_{J}, J_{0}$ and $K_{D}$ parameters for each model. To

458 select the better $\mathrm{Ca}^{2+}-\mathrm{VSD}$ interaction scheme that describes the experimental data, the

459 model fits were compared according to their Akaike Information Criterion (AIC) (Akaike,

460 1974) values, calculated as $\mathrm{AIC}=2 p-2 \ln (L)$, where $p$ is the number of free 
461 parameters and $\ln (L)$ is the maximum log-likelihood of the model. The best model fitting

462 is that achieving the lowest AIC values. Minimum AIC values were used as model selection

463 criteria.

464 The best model fit of the $\mathrm{Ca}^{2+}-$ VSD interaction scheme was extended including two high-

465 affinity $\mathrm{Ca}^{2+}$-binding sites per a-subunit (Figure 2-figure supplement 2D,E). The

466 contribution of each $\mathrm{Ca}^{2+}$-binding site to the free energy of the voltage sensor equilibrium

467 may be split in two, such as $E=E_{S 1} * E_{S 2}=e^{-\left(\Delta \Delta G_{V}^{C a}(S 1)+\Delta \Delta G_{V}^{C a}(S 2)\right) / R T}$, where $E_{S 1}$

468 and $E_{S 2}$ are the allosteric factor $E$ for the RCK1 and RCK2 sites. Thus, for the global fit of

469 the $Q_{\mathrm{C}}\left(V,\left[\mathrm{Ca}^{2+}\right]\right)$ curves, we constrained the allosteric parameter $E_{S 1}$ and $E_{S 2}$ obtained

470 experimentally for the RCK2 $\mathrm{Ca}^{2+}$-sensor mutant (5D5A) and $\mathrm{RCK} 1 \mathrm{Ca}^{2+}$-sensor mutant

471 (D362A/D367A), respectively, as described above. The rest of the parameters $Z_{J}, J_{0}, K_{D 1}$,

$472 K_{D 2}$, and $G$, where $K_{D 1}$ and $K_{D 2}$ are the dissociation constants of the RCK1 and RCK2

473 sites and $G$ is a cooperativity factor between the two sites within the same a-subunit of

474 the BK channel, were allowed to vary freely. 


\section{References}

476 Akaike H. 1974. A new look at the statistical model identification. IEEE Trans Automat

478 Armstrong CM, Bezanilla F. 1974. Charge movement associated with the opening and 479 closing of the activation gates of the Na channels. J Gen Physiol 63:533-552. DOI:10.1085/jgp.63.5.533

481 Bao L, Rapin AM, Holmstrand EC, Cox DH. 2002. Elimination of the BKCa Channel's High-Affinity Ca2+ Sensitivity. J Gen Physiol

120:173-189. DOI:10.1085/jgp.20028627

484 Bao L, Kaldany C, Holmstrand EC, Cox DH. 2004. Mapping the BK Ca Channel's "Ca2+ Bowl." J Gen Physiol 123:475-489. DOI:10.1085/jgp.200409052

Carrasquel-Ursulaez W, Contreras GF, Sepúlveda R V, Aguayo D, González-Nilo F, González C, Latorre R. 2015. Hydrophobic interaction between contiguous residues in the S6 transmembrane segment acts as a stimuli integration node in the BK channel. J Gen Physiol 145:61-74. DOI:10.1085/jgp.201411194

Contreras GF, Neely A, Alvarez O, Gonzalez C, Latorre R. 2012. Modulation of BK

Cox DH, Cui J, Aldrich RW. 1997. Allosteric gating of a large conductance Ca-activated K+ channel. J Gen Physiol 110:257-281. DOI:10.1085/jgp.110.3.257

495 Cui J, Cox DH, Aldrich RW. 1997. Intrinsic voltage dependence and Ca2+ regulation of 496 mslo large conductance Ca-activated K+ channels. J Gen Physiol 109:647-673. DOI:10.1085/jgp.109.5.647

498 Cui J, Aldrich RW. 2000. Allosteric Linkage between Voltage and Ca2+-Dependent 499 Activation of BK-Type mslo1 K+ Channels. Biochemistry 39:15612-15619. 
501 Hite RK, Tao X, MacKinnon R. 2017. Structural basis for gating the high-conductance 502 Ca2+-activated K+ channel. Nature 541:52-57. DOI:10.1038/nature20775

503 Horrigan FT, Cui J, Aldrich RW. 1999. Allosteric voltage gating of potassium channels I.

$504 \quad$ Mslo ionic currents in the absence of Ca2+. J Gen Physiol 114:277-304.

505 Horrigan FT, Aldrich RW. 1999. Allosteric voltage gating of potassium channels II. Mslo

$506 \quad$ channel gating charge movement in the absence of Ca2+. J Gen Physiol 114:305-

507 336. DOI:10.1085/jgp.114.2.305

508 Horrigan FT, Aldrich RW. 2002. Coupling between voltage sensor activation, Ca2+ binding

509 and channel opening in large conductance (BK) potassium channels. J Gen Physiol

$510 \quad$ 120:267-305. DOI:10.1085/jgp.20028605

511 Hou P, Xiao F, Liu H, Yuchi M, Zhang G, Wu Y, Wang W, Zeng W, Ding M, Cui J, Wu Z,

512 Wang L-Y, Ding J. 2016. Extrapolating microdomain Ca2+ dynamics using BK

513 channels as a Ca2+ sensor. Sci Rep 6:17343. DOI:10.1038/srep17343

514 Jiang Y, Lee A, Chen J, Cadene M, Chait BT, Mackinnon R. 2002. Crystal structure and 515 mechanism of a calcium-gated potassium channel 515-522.

516 Jiang Y, Ruta V, Chen J, Lee A, Mackinnon R. 2003. The principle of gating charge 517 movement in a voltage-dependent K channel. Nature 423:42-48.

518 Kshatri AS, Gonzalez-Hernandez AJ, Giraldez T. 2018. Functional validation of Ca2+519 binding residues from the crystal structure of the BK ion channel. BBA - Biomembr 520 1860:943-952. DOI:10.1016/j.bbamem.2017.09.023

521 Latorre R, Castillo K, Carrasquel-Ursulaez W, Sepulveda R V, Gonzalez-Nilo F, Gonzalez 522 C, Alvarez O. 2017. Molecular Determinants of BK Channel Functional Diversity and $523 \quad$ Functioning. Physiol Rev 97:39-87. DOI:10.1152/physrev.00001.2016

524 Latorre R, Vergara C, Hidalgo C. 1982. Reconstitution in planar lipid bilayers of a Ca2+525 dependent $\mathrm{K}+$ channel from transverse tubule membranes isolated from rabbit 526 skeletal muscle. Proc Natl Acad Sci USA 79:805-809. DOI:10.1073/pnas.79.3.805 
527 Lingle CJ. 2007. Gating Rings Formed by RCK Domains: Keys to Gate Opening. J Gen $528 \quad$ Physiol 129:101-107. DOI:10.1085/jgp.200709739

529 Marty A. 1981. Ca-dependent K channels with large unitary conductance in chromaffin $530 \quad$ cell membranes. Nature 291:497-500.

531 Miranda P, Contreras JE, Plested AJR, Sigworth FJ, Holmgren M, Giraldez T. 2013. State532 dependent FRET reports calcium- and voltage-dependent gating-ring motions in BK $533 \quad$ channels. Proc Natl Acad Sci USA 110:5217-5222. DOI:10.1073/pnas.1219611110

534 Miranda P, Holmgren M, Giraldez T. 2018. Voltage-dependent dynamics of the BK 535 channel cytosolic gating ring are coupled to the membrane-embedded voltage $536 \quad$ sensor. Elife 7:e40664. DOI:10.7554/eLife.40664

537 Miranda P, Giraldez T, Holmgren M. 2016. Interactions of divalent cations with calcium 538 binding sites of BK channels reveal independent motions within the gating ring. Proc Natl Acad Sci USA 113:14055-14060. DOI:10.1073/pnas.1611415113

540 Oberhauser A, Alvarez O, Latorre R. 1988. Activation by divalent cations of a Ca2+541 activated $\mathrm{K}+$ channel from skeletal muscle membrane. J Gen Physiol 92:67-86. DOI:10.1085/jgp.92.1.67

543 Pallotta BS, Magleby KL, Barrett JN. 1981. Single channel recordings of Ca2+-activated $544 \quad K+$ currents in rat muscle cell culture. Nature 293:471-474.

545 Pau VPT, Smith FJ, Taylor AB, Parfenova L V, Samakai E, Callaghan MM, Abarca$546 \quad$ Heidemann K, Hart PJ, Rothberg BS. 2011. Structure and function of multiple Ca2+547 binding sites in a $\mathrm{K}+$ channel regulator of $\mathrm{K}+$ conductance $(\mathrm{RCK})$ domain. Proc Natl 548 Acad Sci USA 108:17684-17689. DOI:10.1073/pnas.1107229108

549 Qian X, Niu X, Magleby KL. 2006. Intra- and Intersubunit Cooperativity in Activation of BK 550 Channels by Ca2+. J Gen Physiol 128:389-404. DOI:10.1085/jgp.200609486

551 Rothberg BS, Magleby KL. 1999. Gating kinetics of single large-conductance Ca2+552 activated $\mathrm{K}+$ channels in high $\mathrm{Ca}+$ suggest a two-tiered allosteric gating 
mechanism. J Gen Physiol 114:93-124. DOI:10.1085/jgp.114.1.93

554 Rothberg BS, Magleby KL. 2000. Voltage and Ca2+ activation of single large-conductance

555 Ca2+-activated $\mathrm{K}+$ channels described by a two-tiered allosteric gating mechanism.

$556 \quad J$ Jen Physiol 116:75-99. DOI:10.1085/jgp.116.1.75

557 Savalli N, Pantazis A, Yusifov T, Sigg D, Olcese R. 2012. The contribution of RCK domains

558 to human BK channel allosteric activation. $J$ Biol Chem 287:21741-21750.

$559 \quad$ DOI:10.1074/jbc.M112.346171

560 Schreiber M, Salkoff L. 1997. A novel calcium-sensing domain in the BK channel. Biophys J 73:1355-1363. DOI:10.1016/S0006-3495(97)78168-2

562 Shen KZ, Lagrutta A, Davies NW, Standen NB, Adelman JP, North RA. 1994.

563 Tetraethylammonium block of Slowpoke calcium-activated potassium channels expressed in Xenopus oocytes: evidence for tetrameric channel formation. Pflugers Arch 426:440-445.

566 Smith FJ, Pau VPT, Cingolani G, Rothberg BS. 2012. Crystal structure of a Ba2+-bound 567 gating ring reveals elementary steps in RCK domain activation. Structure 20:2038568 2047. DOI:10.1016/j.str.2012.09.014

569 Smith FJ, Pau VPT, Cingolani G, Rothberg BS. 2013. Structural basis of allosteric 570 interactions among Ca2+-binding sites in a K+channel RCK domain. Nat Commun $571 \quad 4: 1-10$. DOI:10.1038/ncomms3621

572 Stefani E, Ottolia M, Noceti F, Olcese R, Wallner M, Latorre R. 1997. Voltage-controlled 573 gating in a large conductance Ca2+ sensitive K+ channel (hslo). Proc Natl Acad Sci $574 \quad$ USA 94:5427-5431.

575 Sun X, Shi J, Delaloye K, Yang X, Yang H, Zhang G, Cui J. 2013. The Interface between 576 Membrane-Spanning and Cytosolic Domains in Ca2+-Dependent $\mathrm{K}+$ Channels Is 577 Involved in Subunit Modulation of Gating. $J$ Neurosci 33:11253-11261. 578 DOI:10.1523/JNEUROSCI.0620-13.2013 
579 Sweet T-B, Cox DH. 2008. Measurements of the BKCa channel's high-affinity Ca2+

580 binding constants: effects of membrane voltage. J Gen Physiol 132:491-505.

$581 \quad$ DOI:10.1085/jgp.200810094

582 Tao X, Hite RK, MacKinnon R. 2017. Cryo-EM structure of the open high-conductance

583 Ca2+-activated K+ channel. Nature 541:46-51. DOI:10.1038/nature20608

584 Wu Y, Yang Y, Ye S, Jiang Y. 2010. Structure of the gating ring from the human large-

585 conductance Ca2+-gated $\mathrm{K}_{+}$channel. Nature 466:393-397.

$586 \quad$ DOI:10.1038/nature09252

587 Xia X-M, Zeng X, Lingle CJ. 2002. Multiple regulatory sites in large-conductance calcium-

588 activated potassium channels. Nature 418:880-884. DOI:10.1038/nature00956

589 Yang H, Hu L, Shi J, Delaloye K, Horrigan FT, Cui J. 2007. Mg2+ mediates interaction

590 between the voltage sensor and cytosolic domain to activate BK channels. Proc Natl

591 Acad Sci USA 104:18270-5. DOI:10.1073/pnas.0705873104

592 Yang H, Shi J, Zhang G, Yang J, Delaloye K, Cui J. 2008. Activation of Slo1 BK channels

593 by Mg2+ coordinated between the voltage sensor and RCK1 domains. Nat Struct Mol

$594 \quad$ Biol 15:1152-1159. DOI:10.1038/nsmb.1507

595 Yang H, Zhang G, Cui J. 2015. BK channels: multiple sensors, one activation gate. Front $596 \quad$ Physiol 6:1-16. DOI:10.3389/fphys.2015.00029

597 Yang J, Krishnamoorthy G, Saxena A, Zhang G, Shi J, Yang H, Delaloye K, Sept D, Cui 598 J. 2010. An Epilepsy/Dyskinesia-Associated Mutation Enhances BK Channel 599 Activation by Potentiating Ca2+ Sensing. Neuron 66:871-883. 600 DOI:10.1016/j.neuron.2010.05.009

601 Ye S, Li Y, Chen L, Jiang Y. 2006. Crystal Structures of a Ligand-free MthK Gating Ring: 602 Insights into the Ligand Gating Mechanism of K+ Channels. Cell 126:1161-1173. 603 DOI:10.1016/j.cell.2006.08.029

604 Yuan P, Leonetti MD, Pico AR, Hsiung Y, MacKinnon R. 2010. Structure of the Human 
605 BK Channel Ca2+-Activation Apparatus at 3.0 Å Resolution. Science (80- ) 329:182606 186. DOI:10.1126/science.1190414.Structure

607 Yuan P, Leonetti MD, Hsiung Y, MacKinnon R. 2012. Open structure of the Ca2+ gating 608 ring in the high-conductance Ca2+-activated K+ channel. Nature 481:94-97. $609 \quad$ DOI:10.1038/nature10670

610 Zeng X-H, Xia X-M, Lingle CJ. 2005. Divalent Cation Sensitivity of BK Channel Activation

611 Supports the Existence of Three Distinct Binding Sites. J Gen Physiol 125:273-286.

$612 \quad$ DOI:10.1085/jgp.200409239

613 Zhang G, Huang S-Y, Yang J, Shi J, Yang X, Moller A, Zou X, Cui J. 2010. Ion sensing in

614 the RCK1 domain of BK channels. Proc Natl Acad Sci USA 107:18700-18705.

$615 \quad$ DOI: $10.1073 /$ pnas.1010124107

616 Zhang G, Geng Y, Jin Y, Shi J, McFarland K, Magleby KL, Salkoff L, Cui J. 2017. Deletion

617 of cytosolic gating ring decreases gate and voltage sensor coupling in BK channels.

$618 \quad$ J Gen Physiol 149:373-387.

619 Zhou Y, Zeng X-H, Lingle CJ. 2012. Barium ions selectively activate BK channels via the 620 Ca2+-bowl site. Proc Natl Acad Sci USA 109:11413-11418.

$621 \quad$ DOI:10.1073/pnas.1204444109

622 Zhou Y, Yang H, Cui J, Lingle CJ. 2017. Threading the biophysics of mammalian Slo1 623 channels onto structures of an invertebrate Slo1 channel. J Gen Physiol 149:985624 1007. DOI:10.1085/jgp.201711845

625 


\section{Acknowledgments}

627 We thank Mrs. Luisa Soto (University of Valparaiso) for excellent technical assistance. This 628 research was supported by FONDECYT Grant No. 1150273 and AFOSR No. FA9550-16-

629 1- 0384 to R.L.; CONICYT-PFCHA Doctoral fellowships to Y.L.C.; FONDECYT Grant No.

6301180999 to K.C. The Centro Interdisciplinario de Neurociencia de Valparaiso is a Millennium

631 Institute supported by the Millennium Scientific Initiative of the Chilean Ministry of Economy,

632 Development, and Tourism (P029-022-F).

\section{Competing interests}

634 The authors declare no competing financial interests.

635 


\section{Figure 1.}

A
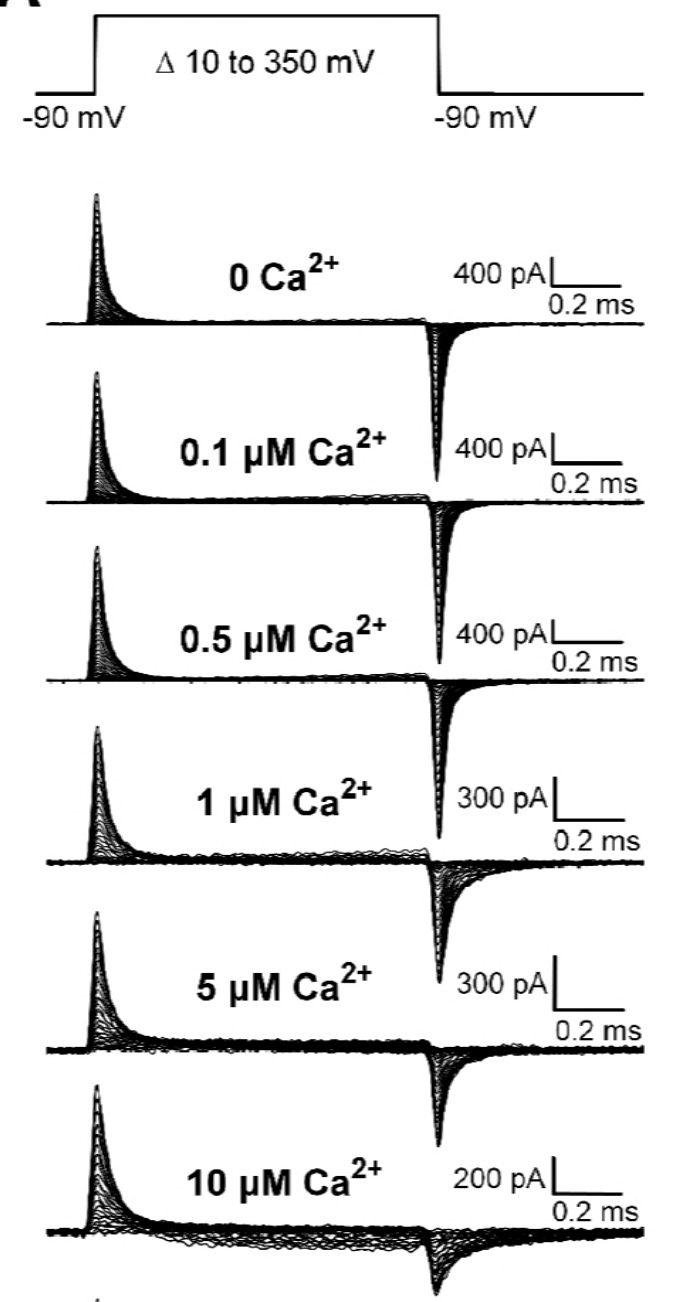

$100 \mu \mathrm{M} \mathrm{Ca}^{2+} \quad 100 \mathrm{pAL} \underset{0.2 \mathrm{~ms}}{\mathrm{~L}}$
B

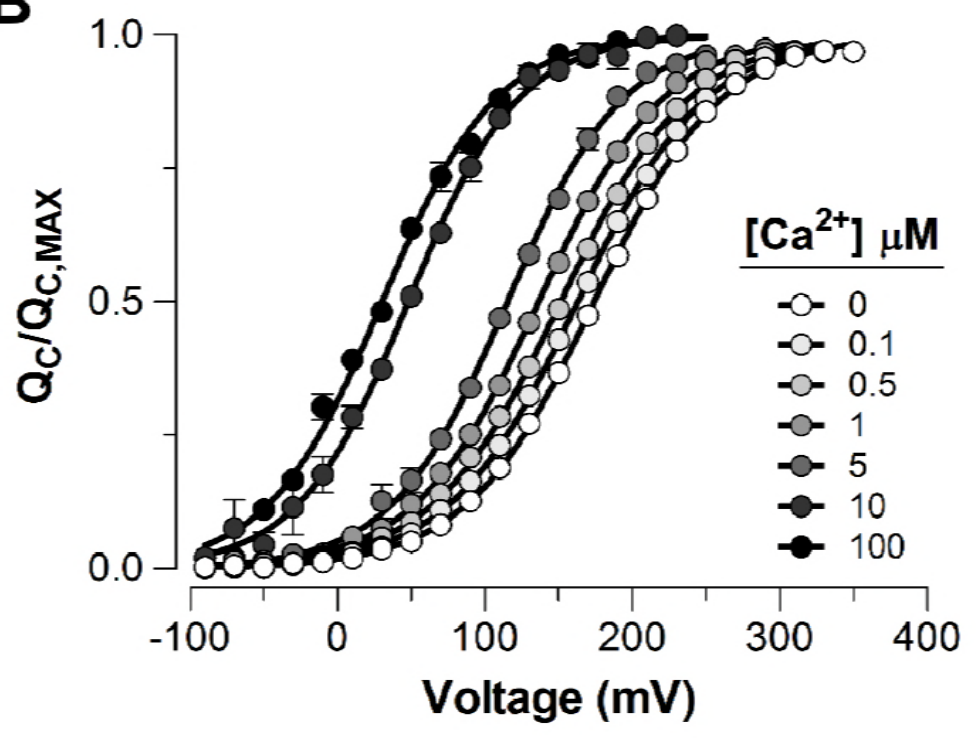

C

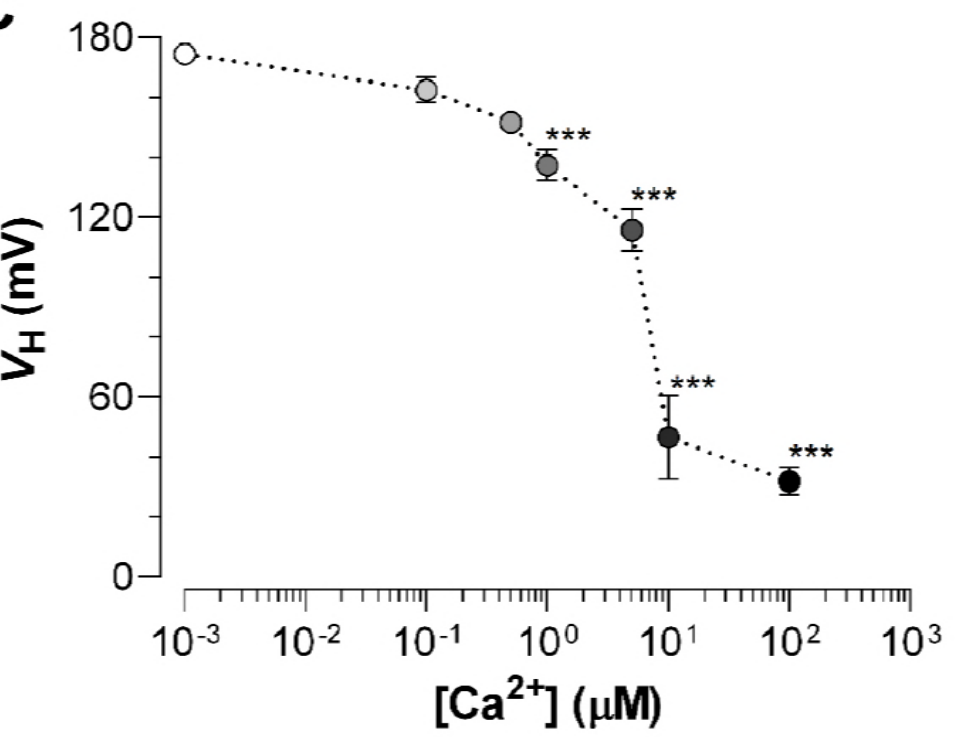


bioRxiv preprint doi: https://doi org/10.1101/520429. this version posted January 16,2019 . The copyright holder for this preprint (which was not certified by peer review) is the author/funder, who has granted bioRxiv a license to display the preprint in perpetuity. It is made available under aCC-BY 4.0 International license.

Figure 2.

A

Scheme I

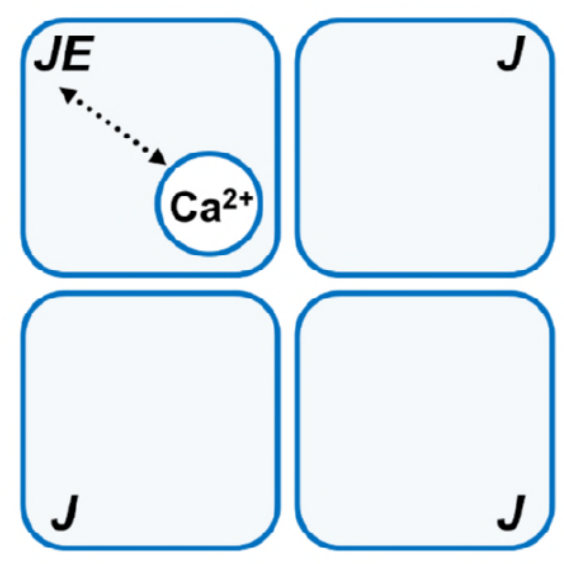

B

Scheme II

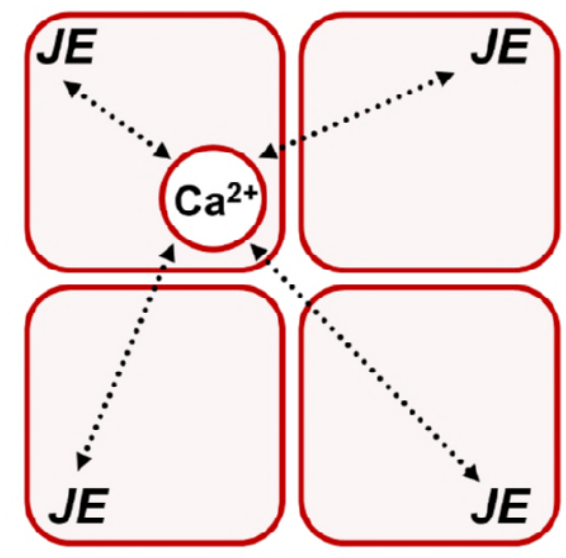

C

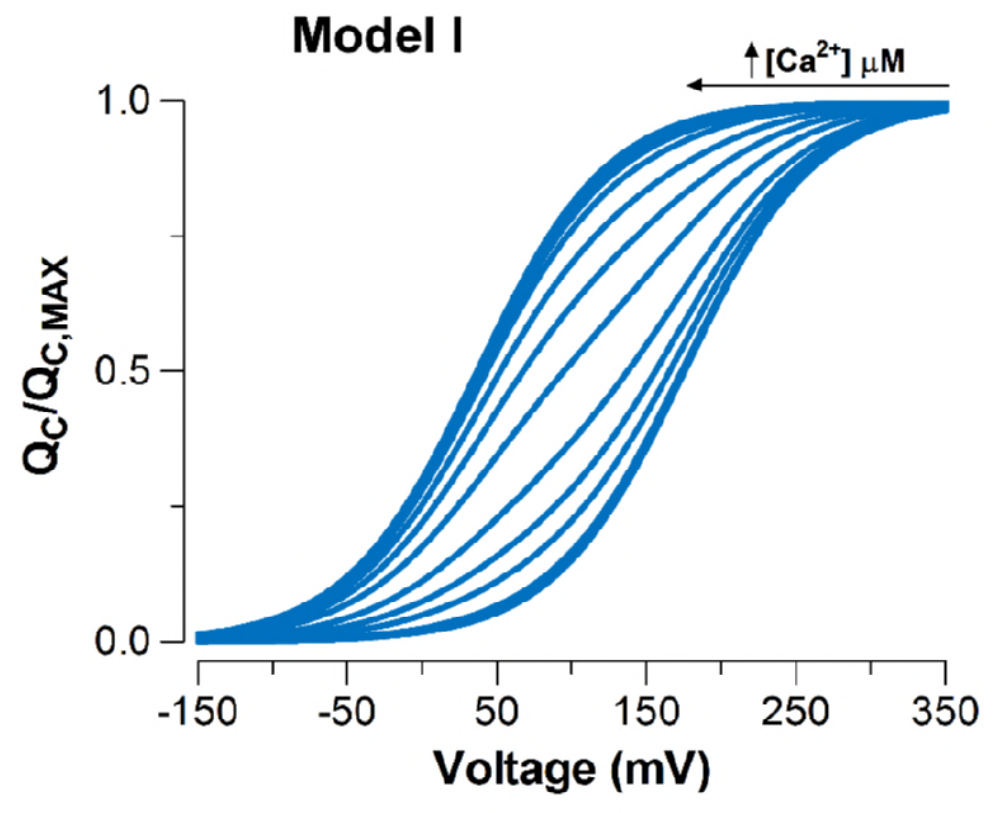

D

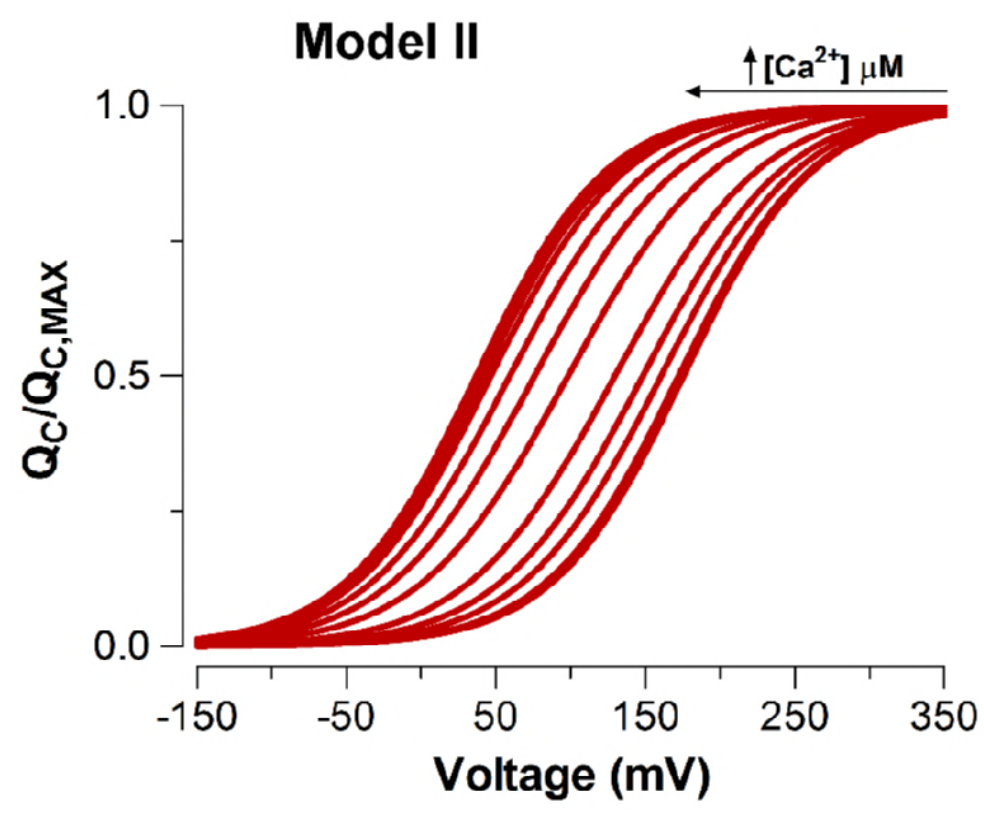


642

A

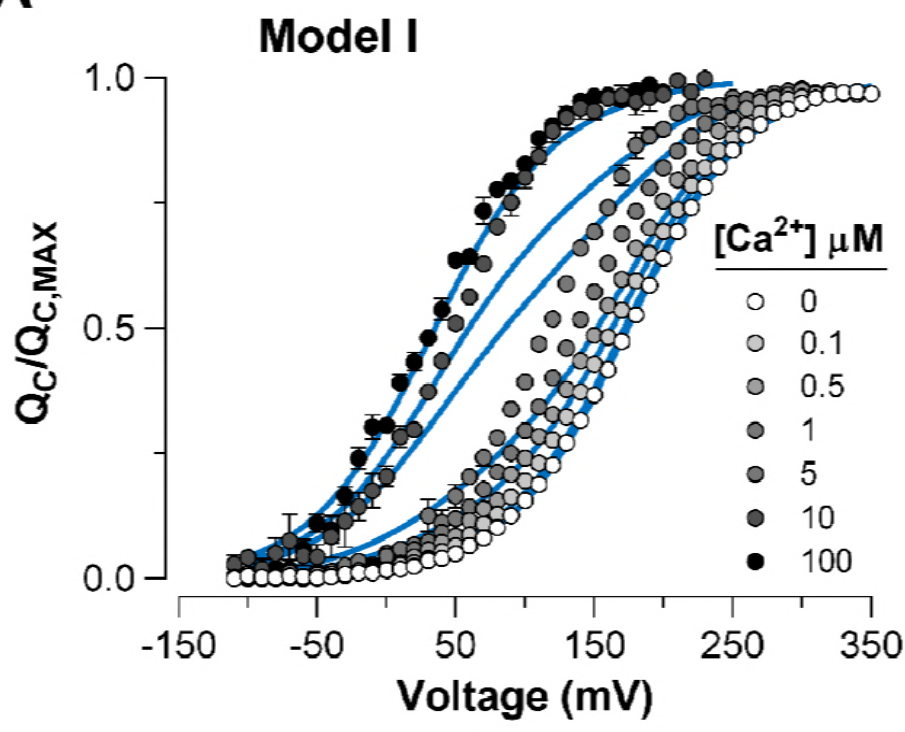

C

\begin{tabular}{lcc} 
Model & $\begin{array}{c}\text { Model I } \\
\text { Parameters }\end{array}$ & Model II \\
\cline { 2 - 3 } $\boldsymbol{Z}_{\boldsymbol{J}}$ & 0.58 & 0.58 \\
$\boldsymbol{J}_{\mathbf{0}}$ & 0.018 & 0.018 \\
$\boldsymbol{E}_{\boldsymbol{M}}$ & $26.4^{*}$ & $2.27^{*}$ \\
$\boldsymbol{K}_{\boldsymbol{D}}(\boldsymbol{\mu M})$ & 3.9 & 4.3 \\
\hline AIC & -784.1 & -946.5 \\
\hline
\end{tabular}

${ }^{*}$ Fixed parameters in the model fitting. AIC values correspond to Akaike Information Criterion to select the best fit model.
B

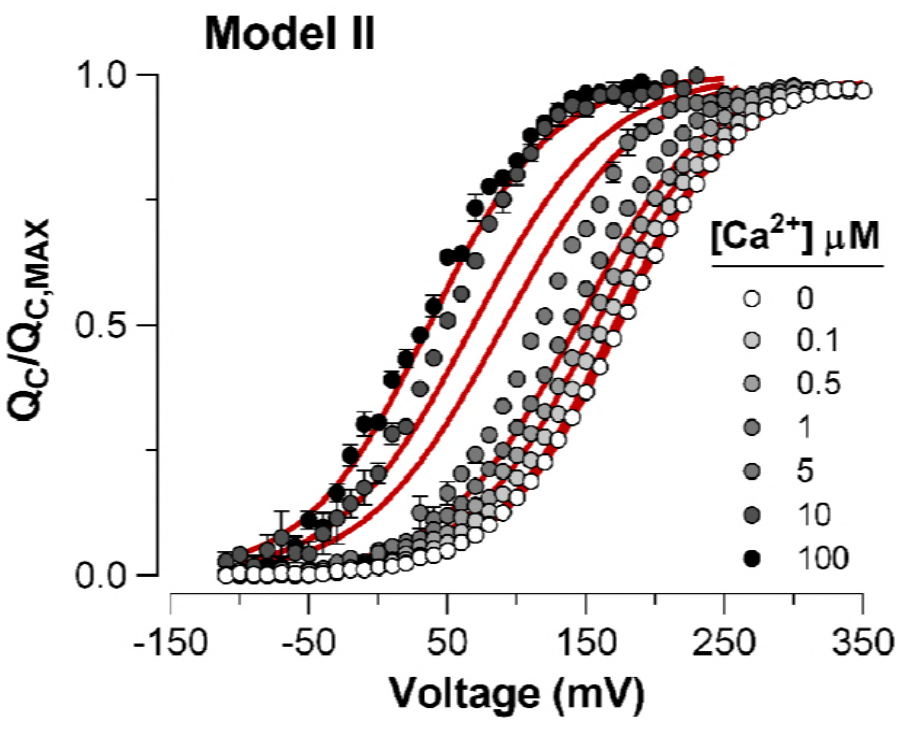

D

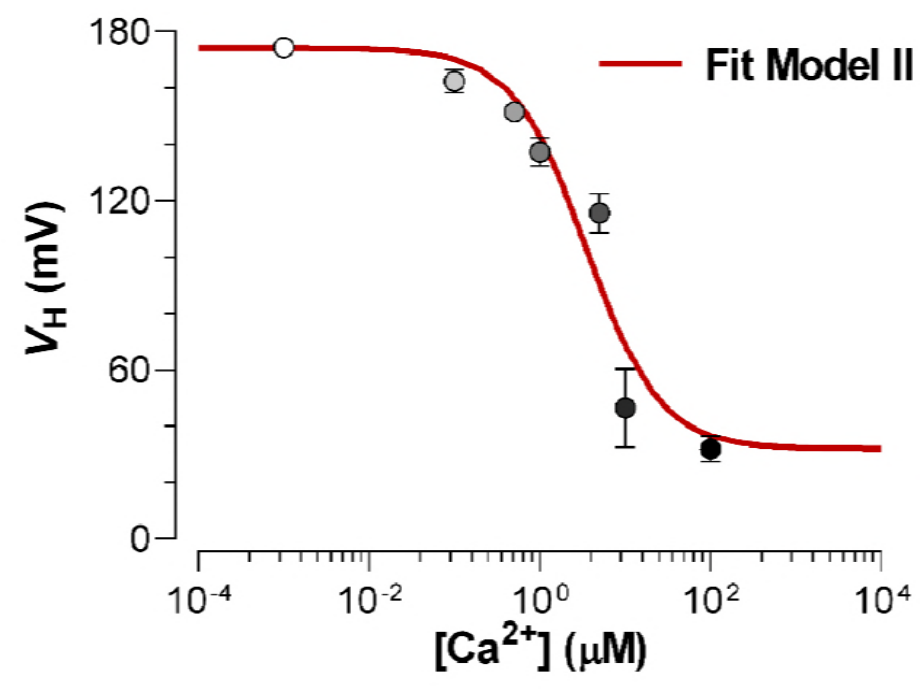


$643 \quad$ Figure 4.

A

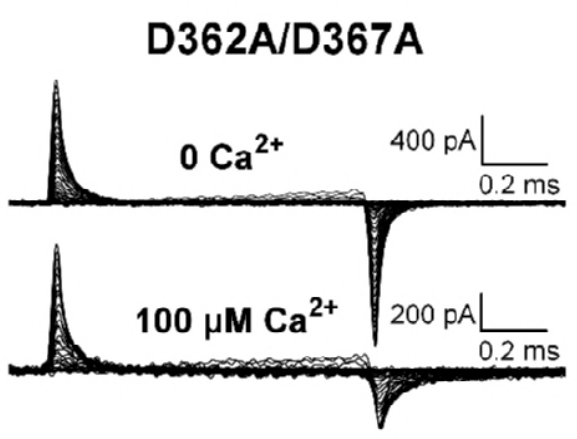

C

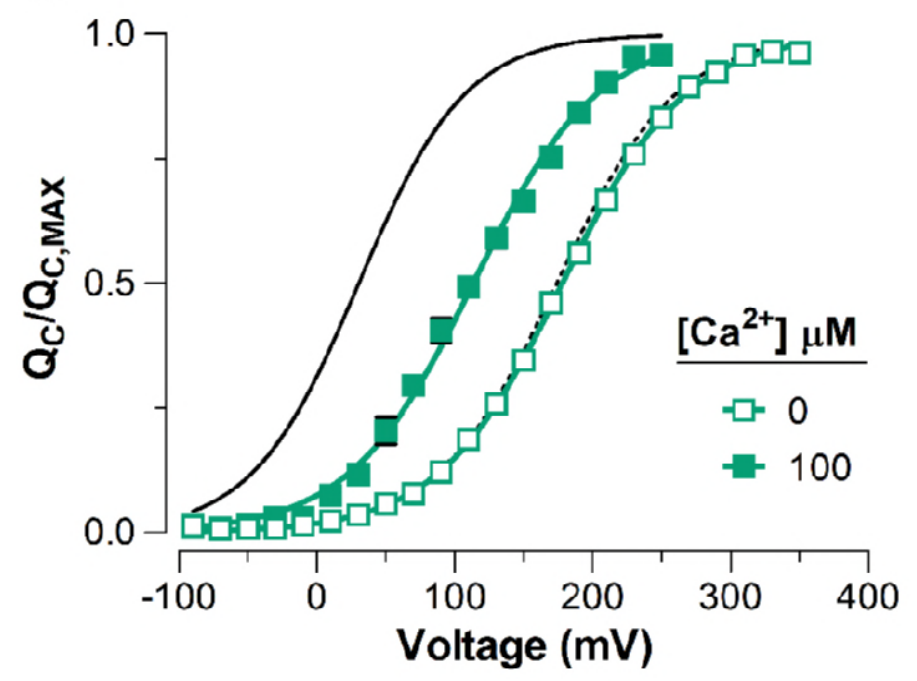

B

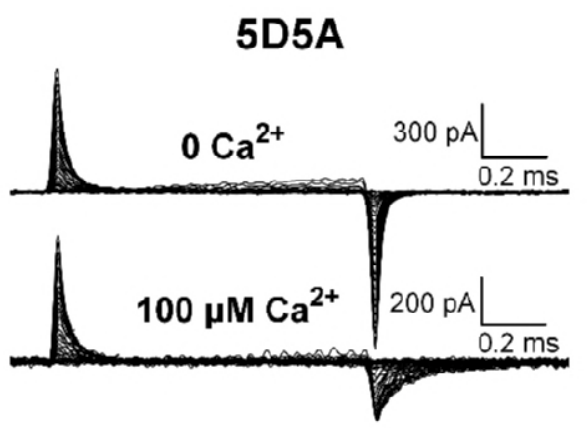

D

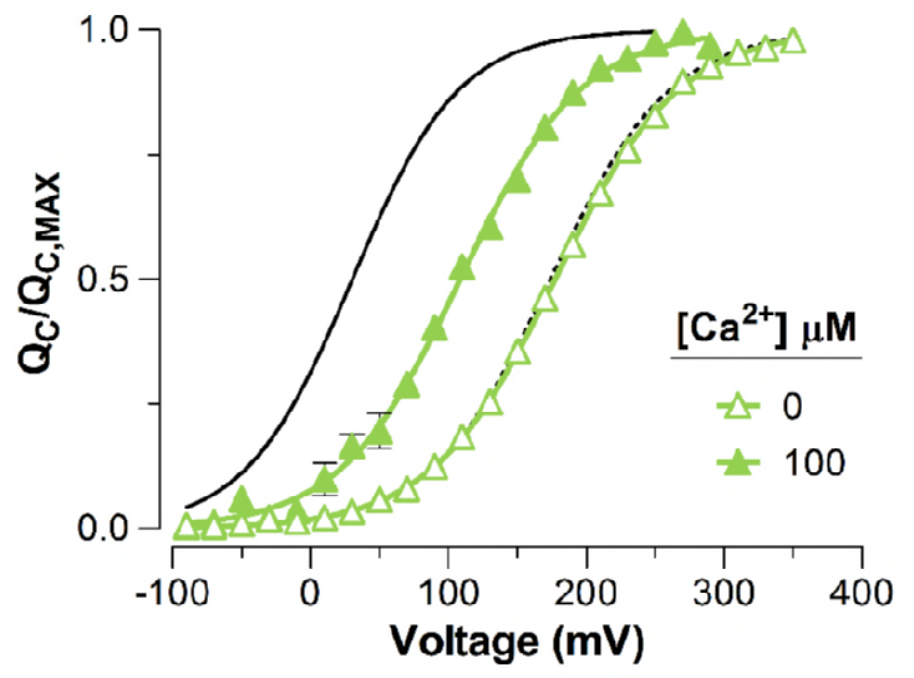

E

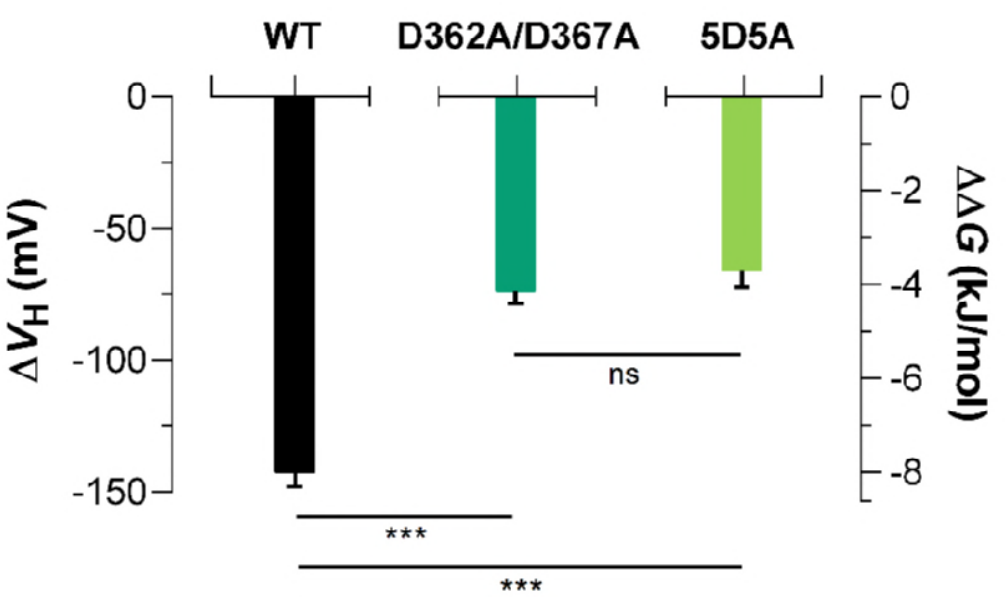

644 


\section{$645 \quad$ Figure 5.}

646

A

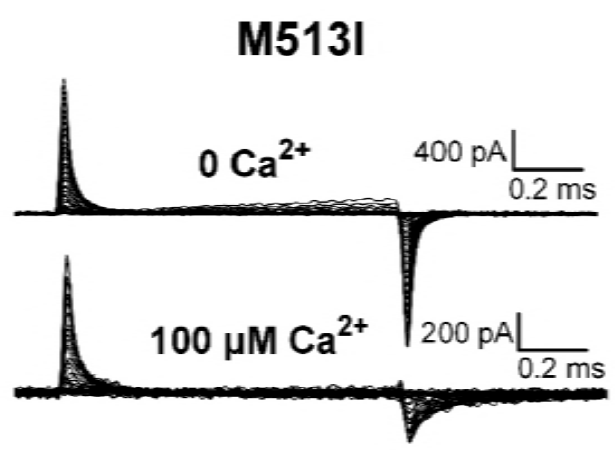

C

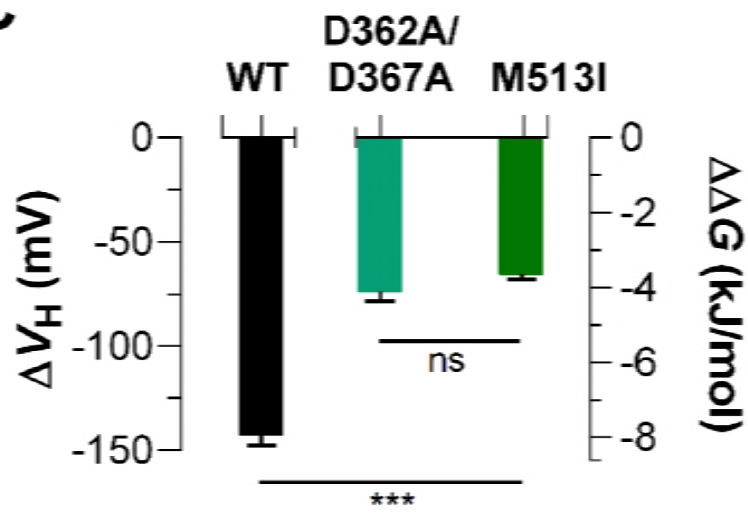

B

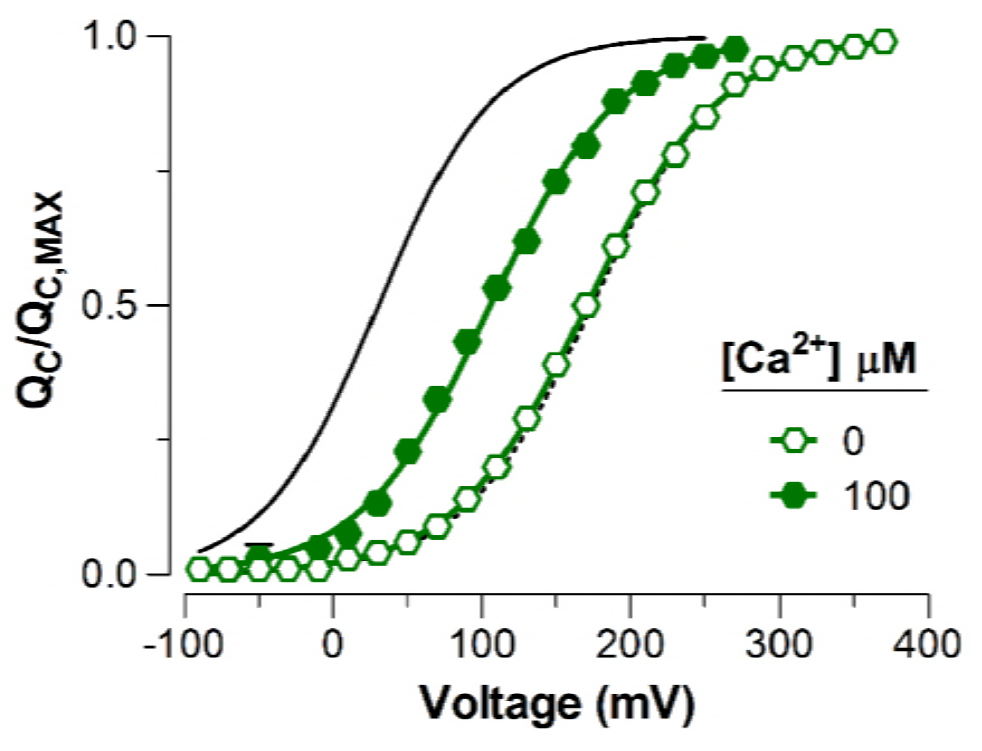




\section{Tables}

648 Table 1. Parameters for the extended $\mathrm{Ca}^{2+}-$ VSD interaction model (Model II) including

649 two high-affinity $\mathrm{Ca}^{2+-b i n d i n g ~ s i t e s ~ p e r ~ a-s u b u n i t . ~}$

650

\begin{tabular}{lcc} 
& \multicolumn{2}{c}{ Model II } \\
\cline { 2 - 3 } $\begin{array}{c}\text { Model } \\
\text { Parameters }\end{array}$ & $\begin{array}{c}\text { With } \\
\text { cooperativity }\end{array}$ & $\begin{array}{c}\text { Without } \\
\text { cooperativity }\end{array}$ \\
\hline $\boldsymbol{Z}_{\boldsymbol{J}}$ & 0.58 & 0.59 \\
$\boldsymbol{J}_{\mathbf{0}}$ & 0.018 & 0.018 \\
$\boldsymbol{E}_{\boldsymbol{S 1}}$ & & $1.46^{*}$ \\
$\boldsymbol{E}_{\boldsymbol{S 2}}$ & & $1.52^{*}$ \\
$\boldsymbol{K}_{\boldsymbol{D} \mathbf{1}}(\boldsymbol{\mu M})$ & 15.6 & \\
$\boldsymbol{K}_{\boldsymbol{D 2}}(\boldsymbol{\mu M})$ & 1.9 & 3.9 \\
$\boldsymbol{G}$ & & 2.8 \\
\hline $\mathbf{A I C}$ & 2.6 & $1^{*}$ \\
\hline
\end{tabular}

* Fixed parameters in the model fitting. AIC values correspond to Akaike Information Criterion to select the best fit model. 


\section{Legends Figures}

652

653

654

655

656

657

658

659

660

661

662

663

664

665

666

667

668

669

670 671 voltage sensor equilibrium constants $(J) E_{M 2}$-fold in all four subunits $\left(E_{M 2}^{4}\right.$, when the four $672 \mathrm{Ca}^{2+}$ sites are occupied). In both schemes, a single $\mathrm{Ca}^{2+}$-binding site is considered in each

Figure 1. Effects of $\mathrm{Ca}^{2+}$-binding on VSD activation in BK channels. (A) Representative gating current $\left(I_{G}\right)$ recordings at different internal $\mathrm{Ca}^{2+}$ concentrations (from 0 to $100 \mu \mathrm{M}$ ). $I_{G}$ were evoked by the indicated voltage protocol of $1 \mathrm{~ms}$ duration. (B) Gating charge-voltage relationships $\left(Q_{\mathrm{C}}(V)\right)$ were obtained by integrating the fast component for each $\mathrm{ON} I_{G}$ trace.

Normalized gating charge data $\left(Q_{\mathrm{C}}(V) / Q_{\mathrm{C}}\right.$, MAX $)$ (mean $\pm \mathrm{SEM}$ ) were fitted using a single Boltzmann function (solid lines). (C) $V_{\mathrm{H}}$ obtained from the $Q_{\mathrm{C}}(V)$ curves as a function of $\mathrm{Ca}^{2+}$ concentration $($ mean $\pm \mathrm{SEM})$. At zero" Ca ${ }^{2+}$ condition $V_{\mathrm{H}\left(0 \mathrm{Ca}^{2+}\right)}=174.5 \pm 2.4 \mathrm{mV}(n$ $=25)$, whereas $\mathrm{Ca}^{2+}$ binding produce a leftward shift in $V_{\mathrm{H}}\left(\Delta V_{\mathrm{H}}\right): 0.1 \mu \mathrm{M} \mathrm{Ca}^{2+}\left(\Delta V_{\mathrm{H}}=-\right.$ $12.1 \pm 3.5 \mathrm{mV}, n=5) ; 0.5 \mu \mathrm{M} \mathrm{Ca}^{2+}\left(\Delta V_{\mathrm{H}}=-22.9 \pm 1.8 \mathrm{mV}, n=5\right) ; 1 \mu \mathrm{M} \mathrm{Ca}^{2+}\left(\Delta V_{\mathrm{H}}=-37.1\right.$ $\pm 3.5 \mathrm{mV}, n=5) ; 5 \mu \mathrm{M} \mathrm{Ca}^{2+}\left(\Delta V_{\mathrm{H}}=-58.8 \pm 6.7 \mathrm{mV}, n=6\right) ; 10 \mu \mathrm{M} \mathrm{Ca}^{2+}\left(\Delta V_{\mathrm{H}}=-127.9 \pm\right.$ $13.9 \mathrm{mV}, n=6) ; 100 \mu \mathrm{M} \mathrm{Ca}^{2+}\left(\Delta V_{\mathrm{H}}=-142.6 \pm 4.5 \mathrm{mV}, n=7\right)$. The one-way ANOVA followed by Dunnett's post-hoc test analysis was used to assess statistical significance of the $\mathrm{Ca}^{2+}-$ induced shifts in $V_{\mathrm{H}}\left({ }^{* * *} p<0.001\right)$.

Figure 2. Model-dependent behavior of the $Q_{\mathrm{C}}(V)$ curves based on the CTD-VSD interaction mechanisms according to the fractional occupancy of $\mathrm{Ca}^{2+}$-binding sites. (A-B) Cartoons representing two interaction schemes between voltage sensors and $\mathrm{Ca}^{2+}-$ binding sites (modify from Horrigan and Aldrich (2002)). The Scheme I (A) assume that $\mathrm{Ca}^{2+}-$ binding only affects the voltage sensor of one $\alpha$-subunit $\left(E_{M_{1}}\right)$. The Scheme II (B) predicts that binding of $\mathrm{Ca}^{2+}$ to one $\alpha$-subunit affects VSD in all subunits equally, increasing the 
673 a-subunit. (C-D) Predictions of $Q_{\mathrm{C}}(V)$ relationships at different internal calcium

674 concentration (from 0 to $10 \mathrm{mM}$ ) by two distinctive interaction mechanisms between $\mathrm{Ca}^{2+}$ -

675 binding sites and voltage sensors (Scheme I and Scheme II), respectively. $Q_{\mathrm{C}}(V)$ curves

676 were generated using Equation 4 (blue: Model I) or Equation 6 (red: Model II), and the

677 following set of parameters: $z_{J}=0.58, J_{0}=0.018, K_{D}=11 \mu \mathrm{M}$ and $E_{M 1}=E_{M 2}^{4}=25$.

678 Figure 3. Dose-dependent effect of $\mathrm{Ca}^{2+}$ on voltage sensor activation is predicted by 679 a $\mathrm{Ca}^{2+}$-VSD interaction mechanism defining that $\mathrm{Ca}^{2+}$-binding equally affects the VSD

680 in all four $\boldsymbol{\alpha}$-subunits. (A-B) The experimental $Q_{\mathrm{C}}(V)$ data were fitted with the two possible

681 allosteric interaction mechanisms between voltage and calcium sensors described by the

682 Scheme I and Scheme II. The blue and red lines represent the global fits by Model I and

683 Model II, respectively. The allosteric factor $E\left(E_{M 1}\right.$ and $\left.E_{M 2}\right)$ was constrained to the value

684 obtained from the individual fitting of the $Q_{\mathrm{C}}(V) / Q_{\mathrm{C}}$, MAX curves at 0 and $100 \mu \mathrm{M} \mathrm{Ca}{ }^{2+}$

685 (experimental $E\left(E_{\text {exp }}\right)$ equal to 26.4). The $Z_{J}, J_{0}$ and $K_{D}$ parameters were allowed to vary

686 freely. (C) Parameters for the best fits of the $Q_{\mathrm{C}}(V)$ data. Note that the allosteric factor $E$

687 for Model I $\left(E_{M 1}\right)$ and Model II $\left(E_{M 2}\right)$ have different interpretations, being $E_{M 2}=E_{\text {exp }}$

688 whereas $E_{M 2}=\sqrt[4]{E_{\text {exp }}}$ given that the four voltage sensor will be altered in 2.3-fold $\left(E_{M 2}=\right.$

689 2.27) with each additional $\mathrm{Ca}^{2+}$ bound. Based on the Akaike Information Criterion (AIC), the

690 best model fit to the $Q_{\mathrm{C}}\left(V,\left[\mathrm{Ca}^{2+}\right]\right)$ data is achieved using the $\mathrm{Ca}^{2+}-\mathrm{VSD}$ interaction scheme

691 described by Model II. (D) The $\mathrm{Ca}^{2+}$-dependence of $V_{\mathrm{H}^{-}}-Q_{\mathrm{C}}(V)$ curves are superimposed

692 with the predicted $V_{\mathrm{H}}$ by Model II (red line).

693 Figure 4. The high-affinity $\mathrm{Ca}^{2+}$-binding sites contribute equally to allosteric coupling

694 between calcium and voltage sensors in BK channels. (A-B) Representative gating 
current $\left(I_{G}\right)$ recordings at 0 and $100 \mu \mathrm{M}$ of $\left[\mathrm{Ca}^{2+}\right]_{i}$ for the RCK1 site mutant (D362A/D367A) and the RCK2 site mutant (5D5A), respectively. (C-D) Gating charge-voltage curves

$697\left(Q_{\mathrm{C}}(V)\right)$ were obtained at $0 \mathrm{Ca}^{2+}$ (open symbols) and $100 \mu \mathrm{M} \mathrm{Ca}^{2+}$ (filled symbols) for 698 D362A/D367A and 5D5A mutants, respectively. Boltzmann fitting to the experimental data 699 (mean \pm SEM) is indicated by solid lines $\left(V_{\mathrm{H}(\mathrm{D} 362 \mathrm{~A} / \mathrm{D} 367 \mathrm{~A})}=178.0 \pm 2.7 \mathrm{mV}, n=12\right.$ and $V_{\mathrm{H}}(5 \mathrm{D} 5 \mathrm{~A})=176.4 \pm 4.6 \mathrm{mV}, n=17$ at "zero" $\mathrm{Ca}^{2+} ; V_{\mathrm{H}}(\mathrm{D} 362 \mathrm{~A} / \mathrm{D} 367 \mathrm{~A})=104.2 \pm 7.3 \mathrm{mV}, n=7$ and $V_{\mathrm{H}}(5 \mathrm{D} 5 \mathrm{~A})=110.8 \pm 6.7 \mathrm{mV}, n=6$ at $\left.100 \mu \mathrm{M} \mathrm{Ca}^{2+}\right)$. For comparison, all $Q_{\mathrm{C}}(V)$ plots

702 include the Boltzmann fit of the $Q_{\mathrm{C}}(V)$ curves for WT at $0 \mathrm{Ca}^{2+}$ (dashed black line) and 100 $703 \mu \mathrm{M} \mathrm{Ca}^{2+}$ (solid black line). (e) Quantification of the $V_{\mathrm{H}}$ shift $\left(\Delta V_{\mathrm{H}}\right)$ in the $Q_{\mathrm{C}}(V)$ curves and 704 the free energy change $\left(\Delta \Delta G_{V}^{C a}\right)$ induced by $100 \mu \mathrm{M} \mathrm{Ca}^{2+}$. The non-parametric $t$-test was 705 used to evaluate statistical significances between WT BK channel and the RCK sites 706 mutants $\left({ }^{* * *} p<0.001 ; \mathrm{ns}\right.$ : non-significant).

Figure 5. Mutations abolishing $\mathrm{Ca}^{2+}$-sensing by the $\mathrm{RCK} 1$ binding-site reduce the

$708 \mathrm{Ca}^{2+}$-induced effect on voltage sensors activation similarly. (A) Representative gating

709 current $\left(\mathrm{I}_{\mathrm{G}}\right)$ recordings at 0 and $100 \mu \mathrm{M}$ of $\left[\mathrm{Ca}^{2+}\right]_{i}$ for the RCK1 site mutant M513I. (B) Gating

710 charge-voltage curves $Q_{\mathrm{C}}(V)$ were obtained at $0 \mathrm{Ca}^{2+}$ and $100 \mu \mathrm{M} \mathrm{Ca}^{2+}$ (open and filled

711 symbols) for the M513I mutant. Boltzmann fitting to the experimental data (mean \pm SEM) is 712 indicated by solid lines $\left(V_{\mathrm{H}}(\mathrm{M} 5131)=170.4 \pm 4.4 \mathrm{mV}, n=17\right.$ at "zero" $\mathrm{Ca}^{2+}$ and $V_{\mathrm{H}}(\mathrm{M} 5131)=$

$713105.0 \pm 6.3 \mathrm{mV}, n=4$ at $\left.100 \mu \mathrm{M} \mathrm{Ca}^{2+}\right)$. For comparison, the $Q_{\mathrm{C}}(V)$ plot includes the

714 Boltzmann fit of the $Q_{\mathrm{C}}(V)$ curves for WT at $0 \mathrm{Ca}^{2+}$ and $100 \mu \mathrm{M} \mathrm{Ca}^{2+}$ (dashed and solid 715 black line). (C) Quantification of the $V_{\mathrm{H}}\left(\Delta V_{\mathrm{H}}\right)$ shift in the $Q_{\mathrm{C}}(V)$ curves and the free energy 716 change induced by $100 \mu \mathrm{M} \mathrm{Ca}^{2+}\left(\Delta \Delta G_{V}^{C a}\right)$. The non-parametric t-test was used to compare 
bioRxiv preprint doi: https://doi org/10.1101/520429. this version posted January 16,2019 . The copyright holder for this preprint (which was not certified by peer review) is the author/funder, who has granted bioRxiv a license to display the preprint in perpetuity. It is made available under aCC-BY 4.0 International license.

717 statistical significances between WT BK channel and the RCK1-site mutants $\left({ }^{* *} \mathrm{p}<0.001\right.$;

718 ns: non-significant). 


\section{Supplementary Information}

720 Assumptions and model predictions. We assume that the four voltage sensors act

721 independently transiting between two states, resting $(R)$ and active $(A)$, governed by the

722 voltage-dependent equilibrium constant $J$. The $\mathrm{R}-\mathrm{A}$ equilibrium is displaced toward the

723 active state by membrane depolarization generating a fast gating charge movement $\left(Q_{\mathrm{C}}\right)$

724 before channels opening. Additionally, the $\mathrm{Ca}^{2+}$-binding to high-affinity sites shifts the 725 voltage sensor equilibrium toward their active configuration through an allosteric coupling

726 described by the factor E (Figure 2-figure supplement 1A). By assuming the simplified

727 standard model for the BK channels (Horrigan and Aldrich, 2002), where each a-subunit has

728 a single $\mathrm{Ca}^{2+}$-binding site, we established the possible states and their connections through

729 which each voltage sensor transit in presence of $\mathrm{Ca}^{2+}$ (Figure 2-figure supplement 1B;C)

730 following the CTD-VSD interaction mechanisms described by the Scheme I and Scheme II

731 (Figure 2A,B).

732 For Scheme I, in which $\mathrm{Ca}^{2+}$-binding sites and voltage sensors can only interact within the

733 same $\alpha$-subunit, the activation of each VSD can occur through the $R_{0}-A_{0}$ or $R_{1}-A_{1}$ transitions

734 according to the functional state of the $\mathrm{Ca}^{2+}$ site (unbound or $\mathrm{Ca}^{2+}$ bound). The equilibrium

735 of such transitions is governed by $J$ or $J E_{M 1}$, respectively (Figure 2-figure supplement

$7362 B$ ). In the case of Scheme II, in which binding of $\mathrm{Ca}^{2+}$ to a single a-subunit affects the four

737 voltage sensors equally, the R-A equilibrium of each VSD would be affected by the number

738 of $\mathrm{Ca}^{2+}$ bound in the channel (0-4) depicted in the model (Model II) as five possible R-A

739 transitions. According to this model, the $J$ constant increase $E_{M 2}$-fold for each occupied $\mathrm{Ca}^{2+}$

740 site (Figure 2-figure supplement 1C). For both schemes, the horizontal transitions R-R

741 and $\mathrm{A}$-A represent the $\mathrm{Ca}^{2+}$-binding equilibrium ( $K$ or $K E$ ) when the VSD is in the resting or 
742 active conformation, respectively. The $K$ equilibrium constant is defined as the

743 bound/unbound probability ratio for each $\mathrm{Ca}^{2+}$-binding site and depends on $\mathrm{Ca}^{2+}$

744 concentration $\left(\left[\mathrm{Ca}^{2+}\right]\right)$ and the $\mathrm{Ca}^{2+}$ dissociation constant $\left(K_{D}\right): K=\left[\mathrm{Ca}^{2+}\right] / K_{D}$.

745 Here, we assume that the voltage sensor movement at ON-gating currents is in equilibrium

746 relative to the binding of $\mathrm{Ca}^{2+}$. The assumption is reasonable since the $\mathrm{Ca}^{2+}$-binding rate

747 constant estimated for BK channel is about $10^{8} \mathrm{M}^{-1} \mathrm{~s}^{-1}$ (Hou et al., 2016) implying that at 10

$748 \mu \mathrm{M}$ internal $\mathrm{Ca}^{2+}$ the association time constant is $1 \mathrm{~ms}$. Thus, $\mathrm{Ca}^{2+}$ binding at this $\mathrm{Ca}^{2+}$

749 concentration proceeds at a pace about 33-fold slower than the voltage sensor movement

$750(\sim 30 \mu \mathrm{s})$. Based on this consideration, the R-A transitions in the models would be

751 predominant transitions whose proportion will be determined by the $\left[\mathrm{Ca}^{2+}\right]$ and $K_{D}$.

752 Therefore, predictions of the $Q_{\mathrm{C}}(V)$ curves at different $\mathrm{Ca}^{2+}$ concentrations for Model I and

753 Model II were based on a given fractional occupancy of $\mathrm{Ca}^{2+}$ sites established by the

754 probability of $\mathrm{Ca}^{2+}$ bound $(b)$ and unbound $(1-b)$ for each $\mathrm{Ca}^{2+}$-sensor, and the energetic

755 contribution to VSD equilibrium.

756 Simulations of the $Q_{\mathrm{C}}(V)$ curves using the Scheme I (Model I) were obtained using the 757 equation

758

$$
\frac{Q_{\mathrm{C}}(V)}{Q_{\mathrm{C}, \mathrm{MAX}}}=(1-b)\left(\frac{1}{1+J^{-1}}\right)+b\left(\frac{1}{1+\left(J E_{M 1}\right)^{-1}}\right)
$$

759 where

760

$$
b=\frac{1}{1+K^{-1}}=\frac{1}{1+\frac{K_{D}}{\left[C a^{2+}\right]}}=\frac{\left[C a^{2+}\right]}{\left[C a^{2+}\right]+K_{D}}
$$




$$
J=J_{0} e^{\frac{z_{J} F V}{R T}}
$$

763 Substituting $b$ and $J$ into Equation (1), the $\mathrm{Ca}^{2+}$-dependent voltage sensor activation for

764 Model I is given by the equation

765

$$
\frac{Q_{\mathrm{C}}(V)}{Q_{\mathrm{C}, \mathrm{MAX}}}=\left(\frac{K_{D}}{\left[C a^{2+}\right]+K_{D}}\right)\left(\frac{1}{1+\frac{e^{\frac{-z_{J} F V}{R T}}}{J_{0}}}\right)+\left(\frac{\left[C a^{2+}\right]}{\left[C a^{2+}\right]+K_{D}}\right)\left(\frac{1}{1+\frac{e^{\frac{-z_{J} F V}{R T}}}{J_{0} E_{M 1}}}\right)
$$

766 Thus, the $Q_{\mathrm{C}}(V)$ curves are determined by the proportion of two functional VSD populations

767 with a distinctive effect (unliganded effect or $\mathrm{Ca}^{2+}$-saturated effect) Consequently, the $768 Q_{\mathrm{C}}(V)$ curves are represented by a weighted sum of two Boltzmann functions.

769 Meanwhile, for the concerted CTD-VSD interaction Scheme II (Model II), the $Q_{\mathrm{C}}\left(V,\left[\mathrm{Ca}^{2+}\right]\right)$

770 curves would be determined using the general equation:

771

$$
\frac{Q_{\mathrm{C}}(V)}{Q_{\mathrm{C}, \operatorname{MAX}}}=\sum_{x=0}^{n}\left(\begin{array}{l}
n \\
x
\end{array}\right)(1-b)^{n-x} b^{x}\left(\frac{1}{1+\left(J E_{M 2}^{x}\right)^{-1}}\right)
$$

772 The expression in the first bracket represents the fraction of VSD belonging to a channel

773 with $x$ (0 to 4 ) $\mathrm{Ca}^{2+}$ bound, according to a binomial probability distribution. Thus, the $Q_{\mathrm{C}}(V)$

774 curves result in a weighted sum of five distinct Boltzmann functions corresponding to the

775 five possible R-A transitions (Figure 2-figure supplement 1C). By stating $n=4$ because

776 the tetrameric symmetry of the channels, and substituting $b$ and $J$ into the previous equation

777 (Equation 5) we have 


$$
\frac{Q_{\mathrm{C}}(V)}{Q_{\mathrm{C}, \operatorname{MAX}}}=\sum_{x=0}^{4}\left(\begin{array}{l}
4 \\
x
\end{array}\right)\left(\frac{K_{D}}{\left[C a^{2+}\right]+K_{D}}\right)^{4-x}\left(\frac{\left[C a^{2+}\right]}{\left[C a^{2+}\right]+K_{D}}\right)^{x}\left(\frac{1}{1+\frac{e^{\frac{-z_{J} F V}{R T}}}{J_{0} E_{M 2}^{x}}}\right)
$$

779 It should be noted that at limiting $\mathrm{Ca}^{2+}$ conditions, both schemes become equivalent where 780 the VSD activation is characterized by a single Boltzmann function. At zero $\mathrm{Ca}^{2+}$, the $Q_{\mathrm{C}}(V)$ 781 curves are described by

$$
\frac{Q_{\mathrm{C}}(V)}{Q_{\mathrm{C}, \operatorname{MAX}}}=\left(\frac{1}{1+\frac{e^{\frac{-z_{J} F V}{R T}}}{J_{0}}}\right) \text {, }
$$

783 whereas $\mathrm{Ca}^{2+}$ saturating concentration $J$ is multiply by the allosteric factor $E$, where $E=$ $784 E_{M 1}=E_{M 2}^{4}$ depending on the model (Model I or Model II):

$$
\frac{Q_{\mathrm{C}}(V)}{Q_{\mathrm{C}, \operatorname{MAX}}}=\left(\frac{1}{1+\frac{e^{\frac{-z_{J} F V}{R T}}}{J_{0} E}}\right)
$$

786 Given that each $\alpha$-subunit has two $\mathrm{Ca}^{2+}$-binding sites, we expanded the CTD-VSD 787 interaction Scheme II (Figure 2-figure supplement 1 C) considering the existence of two $788 \mathrm{Ca}^{2+-b i n d i n g ~ s i t e s ~(F i g u r e ~ 2-f i g u r e ~ s u p p l e m e n t ~ 1 D, E) . ~ T h e ~ M o d e l ~ I I ~ i n c l u d e s ~ t h e ~}$ 789 energetic contribution of RCK1 and RCK2 $\mathrm{Ca}^{2+}$-sites to the VSD activation. The factor $E=$ $790 E_{S 1} * E_{S 2}$ where $E_{S 1}$ and $E_{S 1}$ are the allosteric coupling between the VSD and the RCK1 $791 \mathrm{Ca}^{2+}$-site and $\mathrm{RCK} 2 \mathrm{Ca}^{2+}$-site, respectively. The $K_{1}$ and $K_{2}$ constants define the 792 bound/unbound transition for each RCK1 and RCK2 sites being $K_{1}=\left[\mathrm{Ca}^{2+}\right] / K_{D 1}$ and 
$793 K_{2}=\left[\mathrm{Ca}^{2+}\right] / K_{D 2}$. Assuming that the $\mathrm{Ca}^{2+}$ sensors of distinct $\alpha$-subunit do not interact,

794 we only consider intrasubunit cooperativity between the RCK1 and RCK2 sites defined by

795 the factor $G$. Thus, the occupancy of one RCK site will affect $\mathrm{Ca}^{2+}$-binding equilibrium to the

796 other RCK site in the $\alpha$-subunit $\left(G K_{1}\right.$ and $\left.G K_{2}\right)$ (Figure 2-figure supplement 1E). The

797 equilibrium $J$ of the VSD increase $E_{S 1}$-fold and $E_{S 2}$-fold for the each $\mathrm{Ca}^{2+}$ bound to RCK1

798 and RCK2 sites, respectively, reaching to $J E_{S 1}^{4} E_{S 2}^{4}$ when the eight $\mathrm{Ca}^{2+}$ sites are occupied. 
bioRxiv preprint doi: https://doi.org/10.1101/520429; this version posted January 16,2019 . The copyright holder for this preprint (which was not certified by peer review) is the author/funder, who has granted bioRxiv a license to display the preprint in perpetuity. It is made available under aCC-BY 4.0 International license.

\section{Supplementary Figures}

800 Figure 1-figure supplement 1.

A
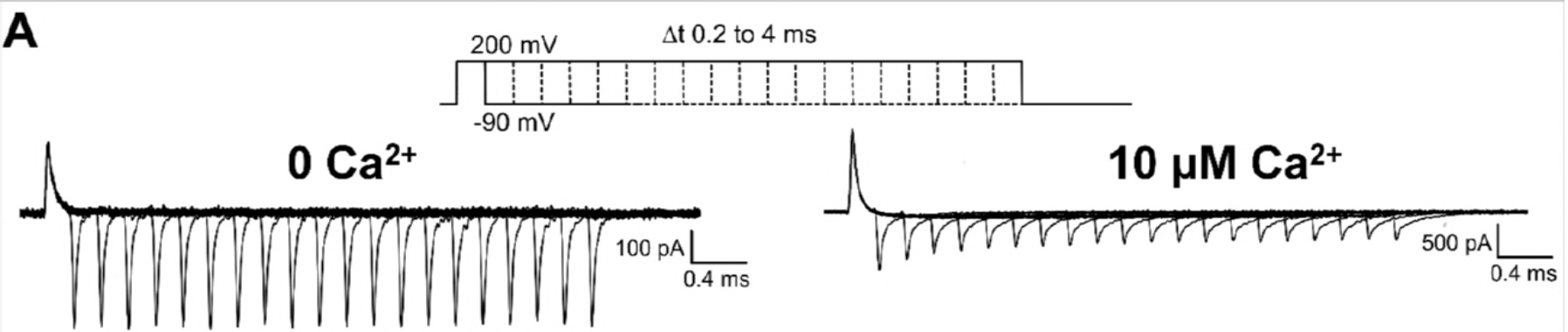

B
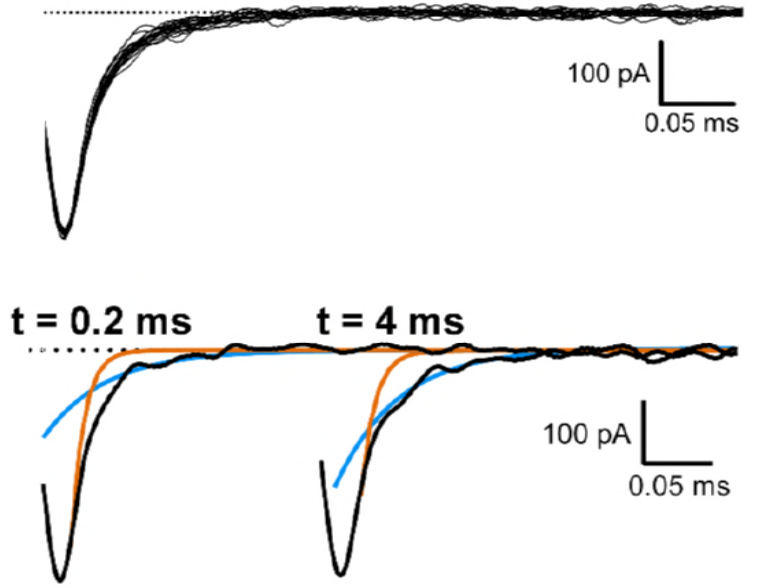

D

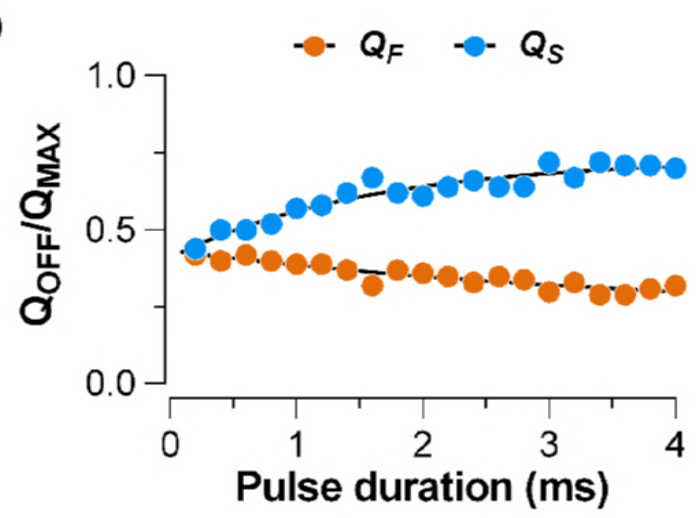

C
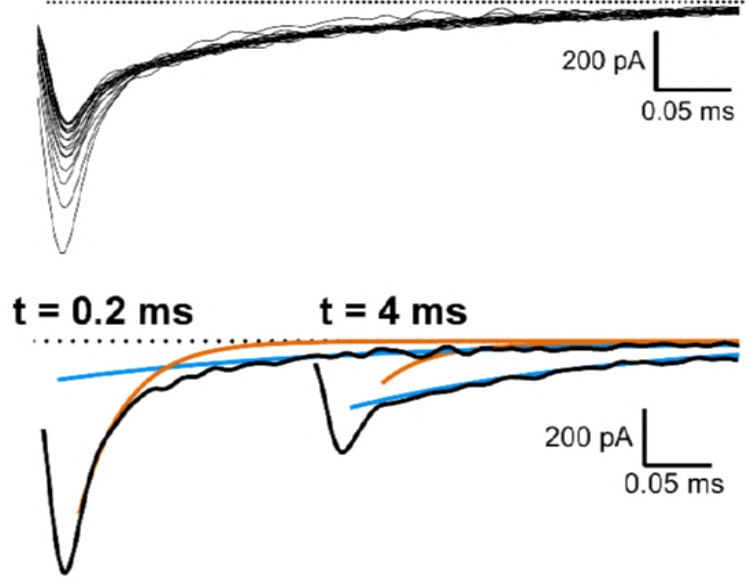

E

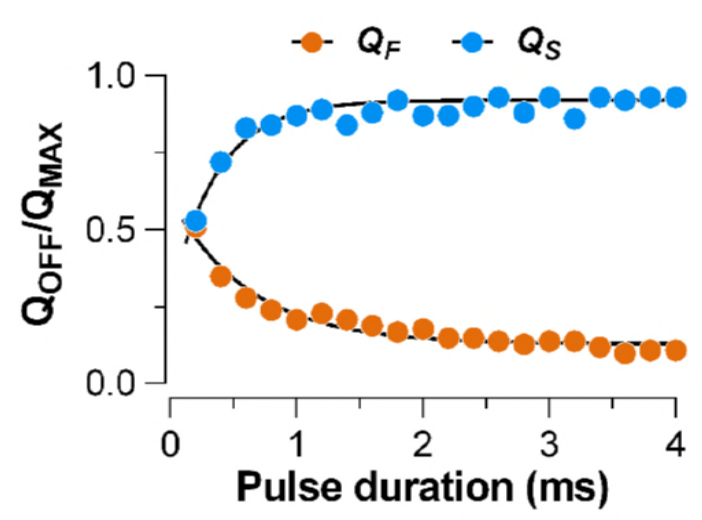

801 
Figure 2-figure supplement 1.

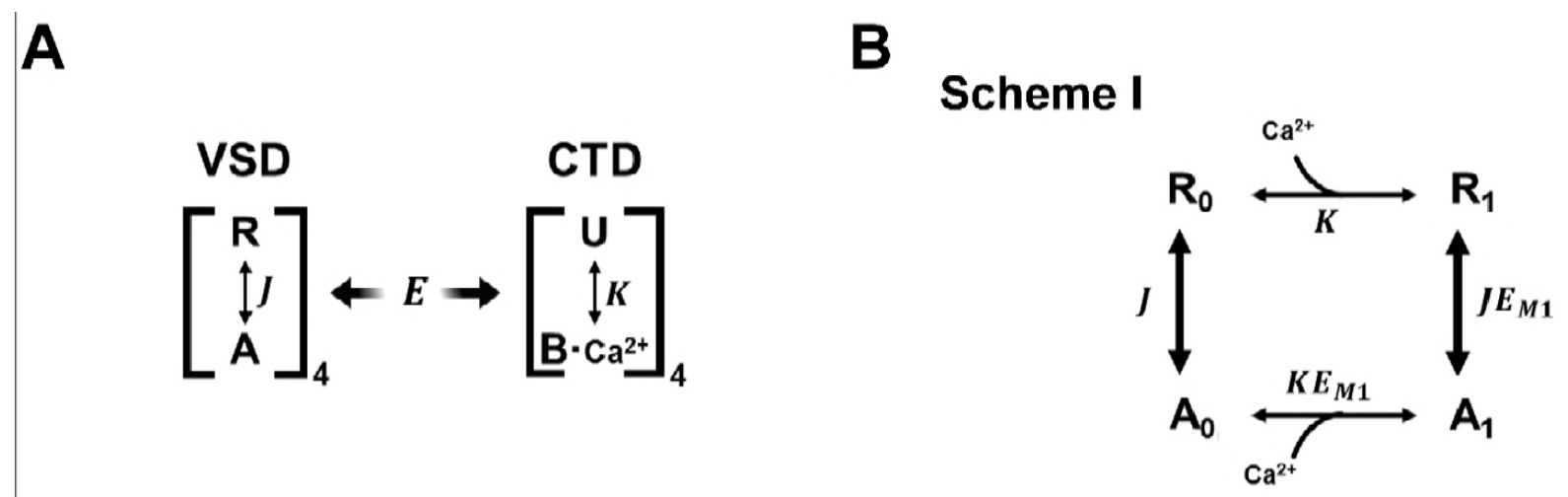

C scheme II

D

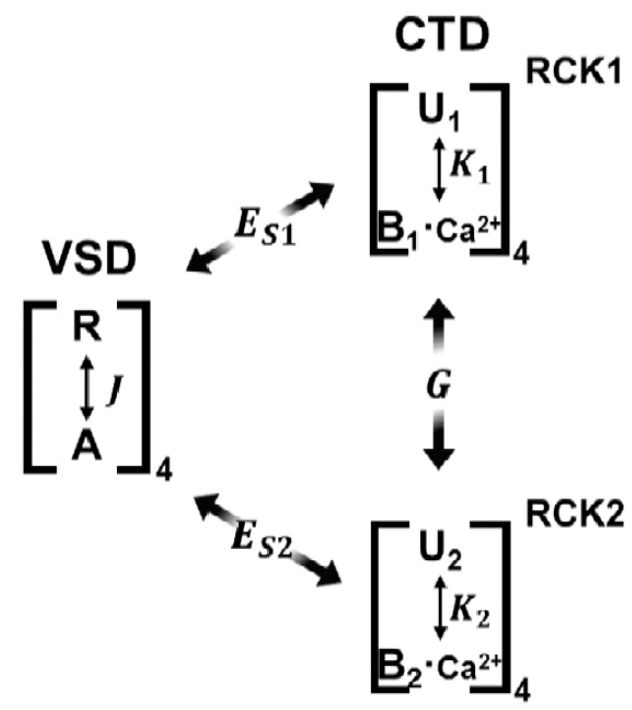

E Scheme II - Two Ca ${ }^{2+}$-Sites

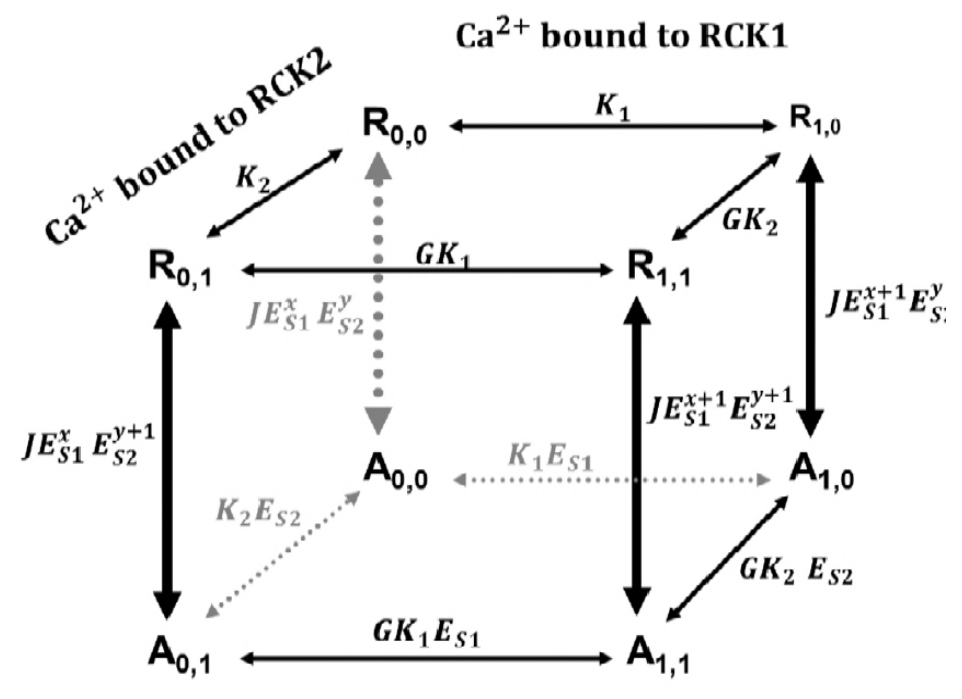

$x=$ from 0 to 3 (number of RCK1 sites occupied inthe other three $\alpha$-subunits) $\mathrm{y}=$ from 0 to 3 (number of RCK2 sites occupied in the other three $\alpha$-subunits) 


\section{Legends Supplementary Figures}

Figure 1-figure supplement $1 . \mathrm{Ca}^{2+}$ increase the slow component of the OFF gating

806 currents. (A) Gating current $\left(I_{G}\right)$ recordings evoked by $200 \mathrm{mV}$ pulses with different 807 durations (from 0.2 to $4 \mathrm{~ms}$ ) at 0 and $10 \mu \mathrm{M}\left[\mathrm{Ca}^{2+}\right]$ conditions, respectively. (B-C) The top 808 panels show the superimposed traces of the $I_{G}$-OFF recorded at $-90 \mathrm{mV}$ evidencing a 809 decrease in amplitude and a slower decay of the OFF current as the duration of the pulse 810 increases at $10 \mu \mathrm{M} \mathrm{Ca}^{2+}$. The dashed line represents the baseline for each experiment. $I_{G-}$ 811 OFF were fitted with an exponential function of two-components (fast and slow 812 components). $I_{G}$-OFF traces at $0.2 \mathrm{~ms}$ and $4 \mathrm{~ms}$ pulse duration are displayed for each $\mathrm{Ca}^{2+}$ 813 condition. Orange and blue lines correspond to fast and slow components of the two814 exponential fits, respectively: (B) "zero" $\mathrm{Ca}^{2+}\left(\tau_{F}=10 \mu \mathrm{s}\right.$ and $\left.\tau_{S}=44 \mu \mathrm{s}\right)$ and (C) $10 \mu \mathrm{M} \mathrm{Ca}{ }^{2+}$ $815\left(\tau_{F}=25 \mu \mathrm{s}\right.$ and $\left.\tau_{S}=212 \mu \mathrm{s}\right)$. (D-E) The relative amplitude of the OFF-charge components, 816 the fast $\left(Q_{F}\right)$ and slow $\left(Q_{S}\right)$ charge components were plotted against the pulse duration and 817 fitted with an exponential function representing the time course of the opening of the 818 channel: (D) "zero" $\mathrm{Ca}^{2+}\left(\tau_{0 \mathrm{Ca}^{2+}}=1.8 \mathrm{~ms}\right)$ and $(\mathbf{E}) 10 \mu \mathrm{M} \mathrm{Ca}^{2+}\left(\tau_{10 \mu \mathrm{M}}=536 \mu \mathrm{s}\right)$.

819 Figure 2-figure supplement 1. Kinetic models of the VSD activation according to the

820 CTD-VSD interaction schemes. (A) Sub-scheme describing calcium and voltage allosteric 821 interaction for closed channels. The VSD transit between two resting $(R)$ and active $(A)$ 822 configuration governed by the equilibrium constant $J$, whereas each $\mathrm{Ca}^{2+}$ site undergoes 823 unbound $(\mathrm{U})-\mathrm{Ca}^{2+}$ bound $(\mathrm{B})$ transitions governed by the equilibrium constant $K$. The 824 allosteric factor $E$ accounts for the coupling between the calcium and voltage sensors (CTD825 VSD) (B-C) VSD kinetic models in presence of $\mathrm{Ca}^{2+}$ according to CTD-VSD interaction 826 schemes I and II (Figure $\mathbf{2 A}, \boldsymbol{B}$ ), respectively, where the vertical transitions (R-A) represent 
827 the VSD movement and the horizontal transitions ( $\mathrm{R}-\mathrm{R}$ and $\mathrm{A}-\mathrm{A})$ are $\mathrm{Ca}^{2+}$-binding reactions

828 when the VSD is in the resting or active conformation. For the Scheme I (B), each VSD can

829 undergo $R_{0}-A_{0}$ or $R_{1}-A_{1}$ transitions depending on the unbound or bound state of the $\mathrm{Ca}^{2+}$ site

830 in the $\alpha$-subunit, respectively. Thus, the $\mathrm{R}_{1}-\mathrm{A}_{1}$ equilibrium is defined by $J$ increased $E_{M 1}$-fold

$831\left(J E_{M 1}\right)$. For the Scheme II $(\mathbf{C})$, the $\mathrm{R}_{0}-\mathrm{A}_{0}$ to $\mathrm{R}_{4}-\mathrm{A}_{4}$ transitions represent the VSD equilibrium

832 with $0,1,2,3$, and 4 occupied $\mathrm{Ca}^{2+}$ sites in the channel. Thus, for each $\mathrm{Ca}^{2+}$ bound the

833 equilibrium constant $J$ increase $E_{M 2}$-fold reaching to $J E_{M 2}^{4}$ when the four $\mathrm{Ca}^{2+}$ sites are

834 occupied. The thickness of the arrows indicates the probability of transitions. (D) General

835 sub-scheme of the CTD-VSD interaction including two $\mathrm{Ca}^{2+}$ sites for each CTD (RCK1 and

836 RCK2 sites). For each RCK1 and RCK2 site the unbound-Ca ${ }^{2+}$ bound transitions are

837 governed by the equilibrium constants $K_{1}$ and $K_{2}$. The factor $G$ describe the cooperativity

838 between the sites within the same a-subunit; and the $E_{S 1}$ and $E_{S 2}$ factors define the

839 allosteric coupling between the RCK1 and RCK2 sites and the VSD, respectively. (E)

840 Schematic representation of VSD kinetic model according to the extended version of the

841 Scheme II (C) accounting for both RCK1 and RCK2 $\mathrm{Ca}^{2+}$-sites on each $\alpha$-subunit. For sake

842 of simplicity, are only depicted the VSD transitions depending on the unbound or bound state

843 of the RCK sites within the same $\alpha$-subunit: $R C K 1$ site $\left(R_{1,0}-A_{1,0}\right), R C K 2$ site $\left(R_{0,1}-A_{0,1}\right)$ and

844 both sites $\left(R_{1,1}-A_{1,1}\right)$. 